\title{
Metabolic Response to the Mitochondrial Toxin 1-Methyl-4-phenylpyridinium (MPP+) in LDH-A/B Double-knockout LS174T Colon Cancer Cells
}

\author{
NZINGA MACK, ELIZABETH MAZZIO, RAMESH BADISA and KARAM F.A. SOLIMAN \\ Pharmaceutical Sciences Division, College of Pharmacy \& Pharmaceutical Sciences, \\ Institute of Public Health, Florida A\&M University, Tallahassee, FL, U.S.A.
}

\begin{abstract}
Background/Aim: Rapid glycolytic substrate-level phosphorylation (SLP) and accumulation of lactic acid are characteristics of diverse cancers. Recent advances in drug discovery have included the use of glycolytic inhibitors with mitochondrial targeting drugs to attempt to invoke an energy crisis in aggressive metabolically active chemo-resistant cancers. In this work, we examine the consequences of inhibiting mitochondrial oxidative phosphorylation (OXPHOS) with 1-methyl-4-phenylpyridinium (MPP+) in LS14T colon cancer cells containing a genetic double knock out (DKO) of lactic acid dehydrogenase (LDHA and LDHB). Materials and Methods: Several metabolic parameters were evaluated concomitant to whole transcriptomic (WT) mRNA, microRNA, and long intergenic non-coding RNAs using Affymetrix 2.1 human ST arrays. Results: MPP + effectively blocked OXPHOS where a compensatory shift toward anaerobic SLP was only observed in the control vector $(C V)$, and not observed in the LDH-A/B DKOs (lacking the ability to produce lactic acid). Despite this, there was an unexpected resilience to $M P P+$ in the latter in terms of energy, which displayed significantly higher resting baseline respiratory OXPHOS capacity relative to controls. At the transcriptome level, MPP+ invoked 1738 differential expressed genes (DEGs) out of 48,226; LDH-A/B DKO resulted in 855 DEGs while 349 DEGs were found to be overlapping in both groups versus respective controls, including loss of mitochondrial complex I (subunits 3 and 6), cell cycle transcripts and
\end{abstract}

This article is freely accessible online.

Correspondence to: Karam FA Soliman, Pharmaceutical Sciences Division, College of Pharmacy \& Pharmaceutical Sciences, Institute of Public Health, Florida A\&M University, Room G 134 H New Pharmacy Building, 1415 ML King Blvd, Tallahassee, FL 32307, U.S.A. Tel: +1 8505993306, e-mail: karam.soliman@famu.edu

Key Words: LDH, glycolysis, mitochondria, cancer cells. fluctuations in epigenetic chromatin remodeling systems. In terms of energy, the effects of $M P P+$ in the $C V$ transcripts reflect the funneling of carbon intermediates toward glycolysis. The LDH-A/B DKO transcripts reflect a flow of carbons away from glycolysis toward the production of acetyl-CoA. Conclusion: The findings from this study suggest a metabolic resilience to $M P P+$ in cancer cells devoid of LDH-A/B, explainable in-part by higher baseline OXPHOS respiratory ATP production, necessitating more toxin to suppress the electron transport chain.

The "Warburg effect" describes an abnormal metabolic phenotype of cancer cells relative to healthy adjacent tissue, evidenced by a high glycolytic rate, over-expression of glycolytic enzymes, a rise in lactic acid production, and a preference for fermentative aerobic glycolysis, with diminished oxygen use by the mitochondria (1). While the original understanding of the Warburg effects deduced a probable mitochondrial defect in cancer cells (2), the current understanding has evolved, particularly with the discovery that glycolytic inhibitors or lactic acid dehydrogenase (LDH) inhibitors such as NCI-066 merely shift metabolic reliance toward greater oxidative phosphorylation (OXPHOS)/ mitochondrial respiration and therefore more efficient production of ATP (3-5). In addition, high levels of oxygen and/or greater mitochondrial biogenesis drive tumorigenic processes (6-8) and appear to be prevalent in the stem cell metabolic phenotype $(9,10)$.

Interestingly, we have been studying the consequences of LDHA inhibitors for many years in diverse tumor cells and repeatedly failed to see any adverse effects on the production of lactic acid or tumor cell energy survival systems, with the only possible consequence being a reduction in cell proliferation (11-13). In collaboration with Dr. Jacques Pouyssegurs laboratory (Nice, France), our recent work further defined transcriptomic changes in colon cancer cells which were genetically engineered to knockout both LDHA/B genes (14), and in doing so, constructed a cell line 
lacking transcripts required to synthesize numerous LDH isoforms (15). That work was crucial in demonstrating the need to simultaneously down-regulate LDH-A and LDH-B genes in order to shut off the production of lactic acid in cancer cells. However, even with this, cancer cells remain immortal, experience slower doubling rates, and exhibit heightened mitochondrial OXPHOS capacity (15).

Findings such as these demonstrate a robust metabolic plasticity inherent to cancer cells that enable a continuous supply of energy produced by either or both glycolytic substrate-level phosphorylation (SLP) or mitochondrial oxidative phosphorylation (OXPHOS) to foster growth and metastasis under various micro-environments (16-18). Cancer cell metabolic rewiring is also a critical factor in driving chemo and radiation-resistant tumors (19, 20), where attempts have been made to combine chemotherapy drugs with metabolic inhibitors associated with anabolic fatty acid synthesis and catabolic oxidation [e.g., stearoylCoA desaturase-1 (SCD1), ATP-citrate lyase (ACLY), acylcoenzyme A synthetase short-chain family member 2 (ACSS2), acetyl CoA carboxylase (ACC), fatty acid synthase (FASN), and Carnitine palmitoyltransferase I (CPT1)](21-23). More recently, there has been a surge in experimentation involving the use of glycolytic or $\mathrm{LDH}$ inhibitors such as (IACS-010759) $(4,18)$ with mitochondrial based targets such as conjugated mitocan based triphenylphosphonium (TPP), BAY87-2243 with drugs such as the biguanide antidiabetics metformin or phenformin (3, $24,25)$.

In this study we explore the metabolic consequences of using a well-known multi-complex mitochondrial complex I, IV inhibitor,1-methyl-4-phenylpyridinium (MPP+) in LDH$\mathrm{A} / \mathrm{B}$ DKO colon cancer cells which are devoid of the metabolic apparatus to carry out anaerobic glycolytic SLP (15).

\section{Materials and Methods}

Materials. Ninety-six well plates, Dulbecco's modified Eagle's medium (DMEM), fetal bovine serum (FBS), penicillin/ streptomycin, general reagents, and supplies were all purchased from Sigma-Aldrich Co. (St. Louis, MO, USA) and VWR International (Radnor, PA, USA). All microarray equipment, reagents, and materials were purchased from Affymetrix/ Thermo Fisher (Waltham, MA, USA).

Cell culture. Dukes' type B, colorectal adenocarcinoma LS174T (ATCC ${ }^{\circledR}$ CL-188 ${ }^{\mathrm{TM}}$ ) WT vector control (VC) versus LDHA/B double knock out (DKO) were established and kindly provided by Dr. Jacques Pouyssegur's facility at the University Cote d'Azur, Lacassagne, Nice, France (15). Cells were cultured in $75 \mathrm{~cm}^{2}$ flasks with high glucose DMEM $(4,500 \mathrm{~g} / \mathrm{l})$ supplemented with $6 \%$ FBS and $100 \mathrm{U} / \mathrm{ml}$ penicillin $\mathrm{G}$ sodium and $100 \mu \mathrm{g} / \mathrm{ml}$ streptomycin sulfate. Cells were grown at $37^{\circ} \mathrm{C}$ in $5 \% \mathrm{CO}_{2}$ and sub-cultured every three to five days. The $\mathrm{CV}$ had a rapid doubling time, produced high lactic acid levels, and grew in multi-cellular aggregates, which required trypsin detachment [Trypsin-EDTA $(0.25 \%)$, phenol red] and pressurized distribution using a $5 \mathrm{ml}$ serological pipette, and subsequent monolayer re-seeding. High glucose DMEM $(4,500 \mathrm{mg} / \mathrm{l})$ was used for all studies, except for monitoring studies to monitor glucose consumption. A switch to low glucose DMEM (1000 mg/l) was required to unmask rapid glucose utilization.

Cell viability. For basic experiments, cells were plated in 96 well plates at $0.5 \times 10^{6}$ cells $/ \mathrm{ml}$. Resazurin (Alamar Blue) indicator dye was used to measure cell viability/metabolic rate (26). Briefly, a working solution of resazurin $(0.5 \mathrm{mg} / \mathrm{ml})$ was prepared in sterile PBS, filtered through a 0.2 -micron filter, added to the samples $[15 \%$ (v/v) equivalent], and returned to the incubator for 2-6 hours. The data were quantified using a Synergy HTX multi-mode reader (BioTek, Winooski, VT, USA) set on $530 \mathrm{~nm}$ (excitation) and $590 \mathrm{~nm}$ (emission) filters.

Lactic acid. Determination of cellular production of lactic acid produced was obtained using a colorimetric enzymatic assay with a lactate reagent according to the manufacturer (Trinity Biotech, Jamestown, NY, USA). The amount of lactic acid was measured in phenol red-free low serum media. The reagent was briefly added to the samples, incubated for 8 minutes, and quantified at $490 \mathrm{~nm}$ using a Synergy HTX multi-mode reader (Bio-Tek).

Glucose consumption. Briefly, cellular glucose consumption was quantified using an enzymatic assay comprised of glucose oxidase $(20 \mathrm{U} / \mathrm{ml})$ and a chromogenic solution and quantified at $490 \mathrm{~nm}$ on a Synergy/HTX multi-mode reader (Bio-Tek) as previously described (15). The data for glucose consumption was calculated as $\%$ of media blanks, housed in the first column of each 96 well.

Somatic cell ATP. Adenosine triphosphate (ATP) was assessed by using the adenosine 5'-triphosphate (ATP) bioluminescent somatic cell assay kit (Catalog Number FLASC) purchased from Sigma Aldrich (St. Louis, MO, USA) carried out according to the manufacturer's instructions. Briefly, the cells were lysed with ATP releasing reagent, transferred to a flat white bottom 96 well plate, and the data was quantified using the Synergy HTX multi-mode reader (Bio-Tek) set on luminescent measurement.

Oxygen consumption. A working solution of Janus Green (0.5 $\mathrm{mg} / \mathrm{ml}$ ) was prepared in sterile PBS and added to the samples [20\% $(v / v)$ equivalent]. Samples were then returned to the incubator to monitor differential profiles in the control group. Janus Green is a dye used to assess mitochondrial activity. As oxygen is consumed, the blue dye changes to a pink color and is quantified using a Synergy HTX multi-mode reader (Bio-Tek) with $530 \mathrm{~nm}$ (excitation)/590 nm (emission). Imaging was performed using an inverted fluorescent microscope under basic settings using the TRITC (red) filter cube.

NADH/NAD+. NADH/NAD+ cellular concentrations were determined according to the manufacturer's protocol (Sigma \#MAK037 NADH/NAD determination kit), and data were quantified using the optical density on a Biotek Synergy MultiMode Reader. NADH concentrations were subtracted from the total $\mathrm{NAD}+$ and $\mathrm{NADH}$ values to obtain NAD+, and data were calculated as a total ratio. 
Lipids. According to the manufacturer's guidelines, lipid isolation was carried out using several methods, including a slight modification of the Folch's extraction procedure consisting of a biphasic solvent system of chloroform/methanol/water in a volumetric ratio of $8: 4: 3(\mathrm{v} / \mathrm{v} / \mathrm{v})$. All lipid studies were carried out under ahigh-fed state with ample glucose supply.

Cholesterol esters. Briefly, the cells were scraped, washed $3 \mathrm{x}$ with cold PBS, and pelleted into micro-centrifuge tubes. $440 \mu \mathrm{l}$ of isopropanol, $280 \mu \mathrm{l}$ of chloroform, and $40 \mu \mathrm{l}$ of NP-40 solution were added to each pellet and samples were homogenized for 30 seconds, spun at $15,000 \times g$ for 10 minutes at $4^{\circ} \mathrm{C}$ and the organic phase transferred to a new tube, then dried at $50^{\circ} \mathrm{C}$. The determination of cholesterol/ cholesteryl esters was carried out using Abcam product \#ab102515 (Cambridge, MA, USA) according to the manufacturer's guidelines and quantified using a Synergy HTX multi-mode reader (Bio-Tek) with $530 \mathrm{~nm}$ (excitation)/590 nm (emission).

Triglycerides. Briefly, the cells were scraped, washed $3 \times$ with PBS, and pelleted into microcentrifuge tubes. According to the manufacturer guidelines, triglycerides were determined using Abcam product \#ab65336. After adding NP-40 solution and subjecting the samples to a series of heat cycles at $100^{\circ} \mathrm{C}$, the upper layer was combined with assay buffer and lipase, placed on a rocker shaker for 20 minutes, followed by addition of a detection reagent, incubation for 1 hour and quantification using a Synergy HTX multi-mode reader (Bio-Tek) with the following settings: $530 \mathrm{~nm}$ (excitation)/590 nm (emission).

Neutral lipids. Briefly, the cells were scraped, washed $3 \times$ with PBS, and pelleted into microcentrifuge tubes. According to the manufacturer guidelines, neutral lipids were determined using Abcam \#ab242307. After pelleting, $200 \mu \mathrm{l}$ methanol and $400 \mu \mathrm{l}$, chloroform was added before homogenization. $150 \mu \mathrm{ls}$ of pure water was added to the samples, followed by vortexing and centrifuging at $1000 \times g$ for $5 \mathrm{~min}$. Approximately $150 \mu \mathrm{l}$ of the lower layer was isolated into a glass vial and left to evaporate $\left(55^{\circ} \mathrm{C}\right)$, then reconstituted to $150 \mu \mathrm{l}$ with isopropanol. Subsequently, $40 \mu \mathrm{ls}$ of that sample was collected, and neutral lipids were determined using Abcam \#ab242307 carried out according to the manufacturer guidelines. Neutral lipids were quantified using a Synergy HTX multi-mode reader (Bio-Tek) with the following settings: $480 \mathrm{~nm}$ (excitation)/580 nm (emission).

Microarray WT 2.1 human datasets. After the experimental treatment, the cells were scraped, washed three times in ice-cold HBSS, spun down, the supernatant removed, and the remaining pellet was rapidly frozen and stored at $-80^{\circ} \mathrm{C}$. Total RNA was isolated and purified using the Trizol/chloroform method. The RNA quality was assessed, and concentrations were equalized to $82 \mathrm{ng} / \mu \mathrm{l}$ in nuclease-free water. According to the GeneChipTM WT PLUS Reagent Manual for Whole Transcript (WT) expression arrays, whole transcriptome analysis was conducted. Briefly, RNA was reverse transcribed to first strand /second strand cDNA followed by cRNA amplification and purification. After 2nd cycle ss-cDNA Synthesis and hydrolysis of RNA, ss-cDNA was assessed for yield, fragmented, labeled, and hybridized onto the arrays before being subjected to fluidics and imaging using the Gene Atlas (Affymetrix, ThermoFisher Scientific). The array data quality control and initial processing from CEL to CHP files were conducted using an expression console before data evaluation, using the Affymetrix transcriptome analysis console, String Database (String Consortium 2020), and DAVID functional annotation microarray tools (27-29). The dataset has been deposited to NIH Gene Expression Omnibus located at https://www.ncbi.nlm.nih.gov/geo/query/acc.cgi?acc=GSE149289.

Data analysis. Statistical analysis was performed for basic studies using GraphPad Prism (version 3.0; Graph Pad Software Inc., San Diego, CA, USA). Significant differences between the groups were assessed using either the student's $t$-test or one-way ANOVA, followed by Tukey's post hoc analysis.

\section{Results}

The effects of MPP+ (0.014-7.4 mM) on basic metabolic parameters in both control vectors $(\mathrm{CV})$ (Figure 1A) and LDH-A/B DKO cells (Figure 1B) were determined, including viability/metabolic rate, ATP, cell respiration, glucose use, and lactic acid production. The study's high glucose requirement $(4,500 \mathrm{mg} / \mathrm{l})$ in Figure 1 becomes a critical control issue because a high plating cell density in a micro-titer plate containing finite glucose, when employing a mitochondrial toxin, will trigger rapid glycolysis/ exhaustion of glucose supplies and therefore indirect cell death. The effects of MPP+ observed in the CV are well within the bounds of what we have observed in diverse cancer cells over the years (Figure 1A) (30). This includes a compensatory reliance on SLP in glycolysis to sustain ATP levels coinciding with the rise in lactic acid and a gradual accelerated decline in glucose concentration. We anticipated that treating the LDH-A/B DKO cells with MPP+ would be catastrophic, simply because blocking both OXPHOS and SLP should evoke an energy crisis. However, on the contrary, the death curve in the LDH$\mathrm{A} / \mathrm{B}$ was relatively mild, with very little difference from the $\mathrm{CV}$, as shown in Figure 1A. After repeating this work several times, we ultimately figured that the baseline differential between the $\mathrm{CV}$ of Figure 1 is inherently different from the LDH-A/B DKO in terms of OXPHOS resting capacity, shown as $\%$ control. In Figure $2 \mathrm{~A}$, we show the resting differential in OXPHOS between the CV and the LDH-A/B DKO by relative fluorescence and corresponding images evaluated with Janus Green: B (1) CV and B (4) LDHABDKO, where it becomes evident that the cellular respiration rate of the LDA-A/B DKO cell lines is amplified at baseline. Here we show that the $\mathrm{CV}$ group mitochondria are very close to being completely shut down by $116 \mu \mathrm{M}$ of MPP+ [Figure 2B (2)] and fully suppressed at $463 \mu \mathrm{M}$ [Figure 2B (3)].In contrast, in the LDH-A/B DKO, even at $1.8 \mathrm{mM} \mathrm{MPP}+$, the cells are still respiring, which coincides with the data obtained in Figure 1.

Further studies were conducted to determine the inherent metabolic differences between the $\mathrm{CV}$ and the LDH-A/B DKO in resting untreated cells (Figure 3 ). The data show that the $\mathrm{CV}$ uses glucose rapidly and produces abundant lactic acid (Figure 
A

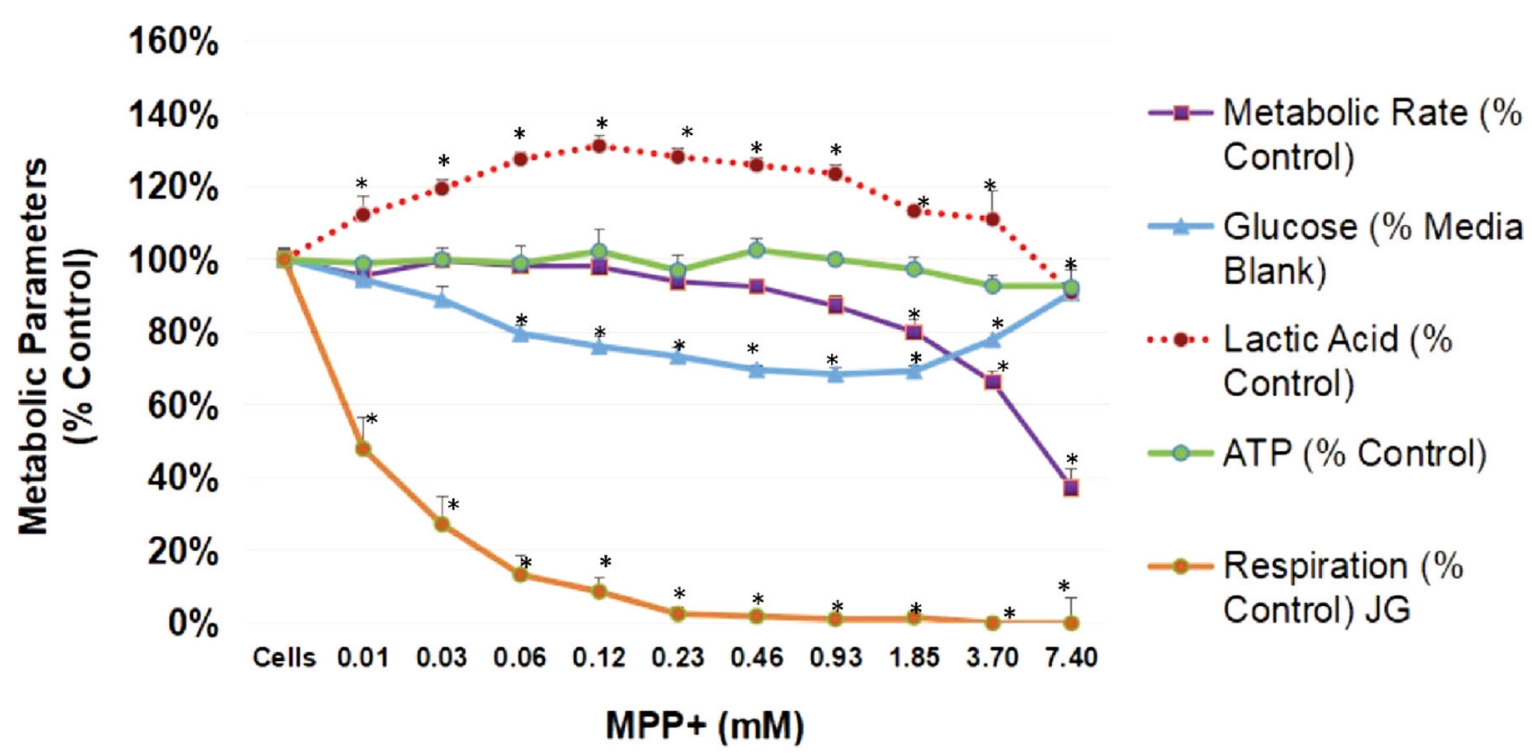

B

$160 \%$

$140 \%$

- - Metabolic Rate (\% Control)

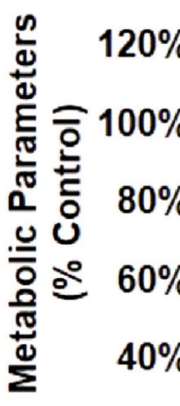

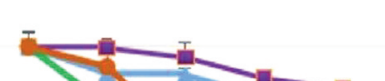

$\simeq$ Glucose (\% Media Blank)

- - - Lactic Acid (\% Vector Control)

$\leadsto$ ATP (\% Control)

$20 \%$

$0 \%$

Cells $0.01 \quad 0.03 \quad 0.06 \quad 0.12 \quad 0.23 \quad 0.46 \quad 0.93 \quad 1.85 \quad 3.70 \quad 7.40$

$\rightarrow$ Respiration (\% Control) JG

\section{$\mathrm{MPP}+(\mathrm{mM})$}

Figure 1. Metabolic profile of response to MPP+ (0.014-7.4mM) in the control vector (CV) (1A) vs. LDHA/B-DKO LS174T cells cultured in high glucose media $(1 B)$. The data represents the mean $\pm S E M, n=4$ for metabolic rate (viability) as \% control, glucose utilization as $\%$ of glucose concentrations in a media blank, lactic acid production as \% of lactic acid in the CV cell line, cell respiration as \% of control and ATP produced as \% of control. Significant differences between the control and MPP+ treatment was determined by a one-way ANOVA, followed by a Tukey post hoc test, ${ }^{*} p<0.05$.

3A), which is opposite to the LDH-A/B DKOS, which show little to no glucose use, and a complete absence of lactic acid. Even though there was a dramatic metabolic divergence between how the CVs and LDH-A/B DKOs produce energy, the NADH to NAD+ ratio appears to follow a steady-state equilibrium (Figure 3B). The basic lipid profiles between the two cell lines do not vary significantly under a high glucose fed state for either neutral lipids or cholesterol esters (Figure 4B, C) with a slight increase in intracellular triglycerides (Figure 4A). As to the direct involvement of metabolic rewiring 
A

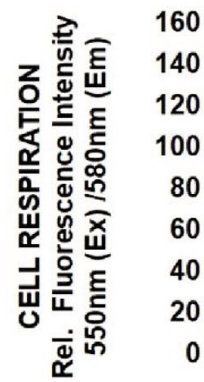

$B(1)$

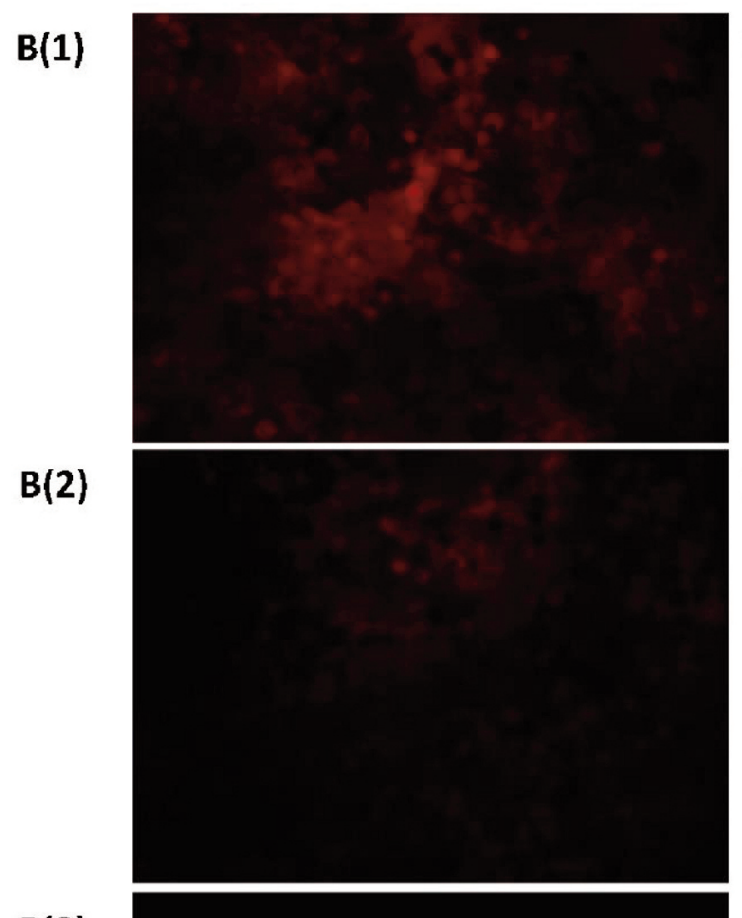

$*$

$B(4)$

$\mathrm{B}(3)$

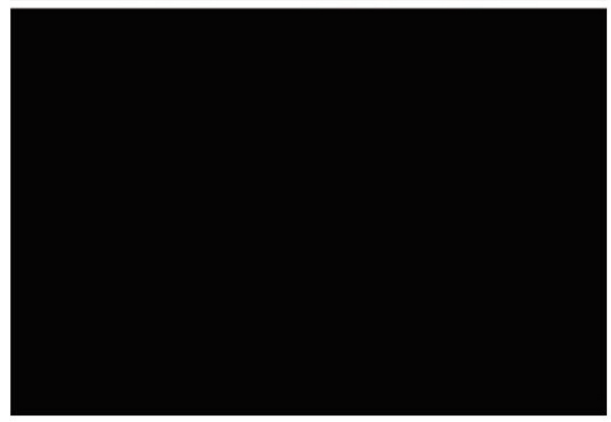

$\mathbf{B}(5)$

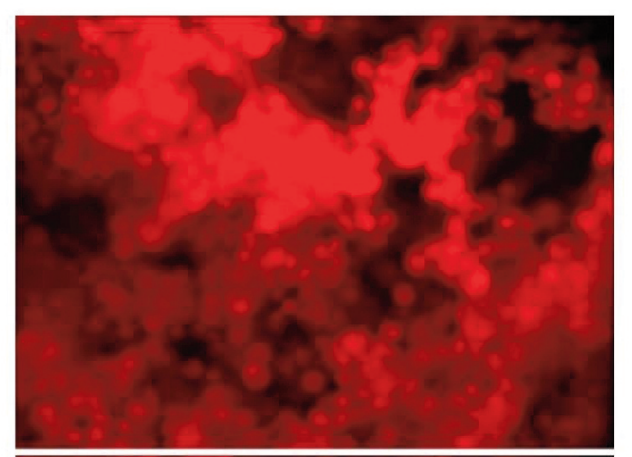

\section{LDH-A/B DKO}

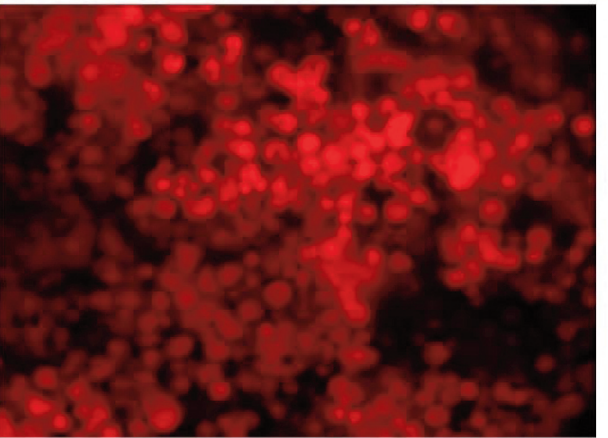

$B(6)$

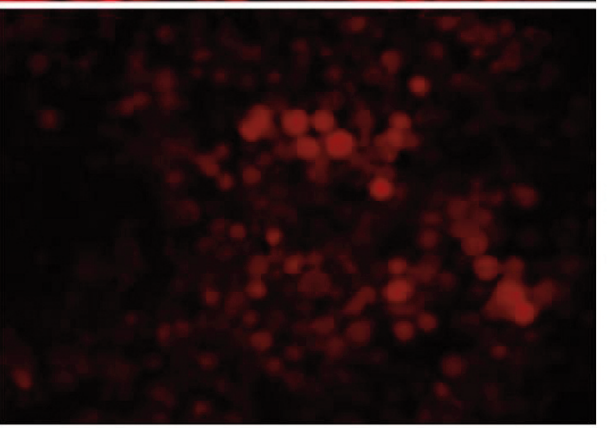

Figure 2. Differential cellular respiratory profile in the CV vs. LDH-A/B DKO LS174T cells cultured in high glucose media. The data are expressed as mean $\pm S E M, n=4$, for cell respiration with significant differences between the $C V$ and the $L D H-A / B$ DKO determined by student's $t$-test, ${ }^{*} p<0.05, n=4$. (A) Fluorescent images represent higher intensity (cellular respiration). (B), where the data represent $B(1):(C V), B(2): C V$ with $116 \mu M M P P+, B$ (3): $C V$ with $463 \mu M M P P+, B(4): L D H-A B / D K O$ controls, B (5): LDHA/B DKO with 463 $M M M P P+$ and B (6): LDHAB DKO with 1.8 mM MPP+.

in the LDH-A/B DKO resting $v s$. CV to use fats for energy, further studies will be required to understand this aspect fully.

Next, optimal concentrations of MPP+ were established to conduct comparative microarray transcriptomic analysis, which we set at $231 \mu \mathrm{M} \mathrm{MPP}+, \mathrm{n}=3$ (Figure 5). An overall summary of differentially expressed genes (DEGs) evoked by MPP+ in CV or LDH-A/B DKOs was conducted. Out of 48,226 gene transcripts tested, there were 1738 DEGs by 


\section{A}

- Extracellular Glucose $\square$ Extracellular Lactic Acid

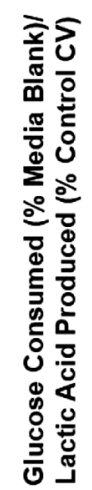
$120 \%$

$100 \%$

$80 \%$

$60 \%$

$40 \%$

$20 \%$

$0 \%$

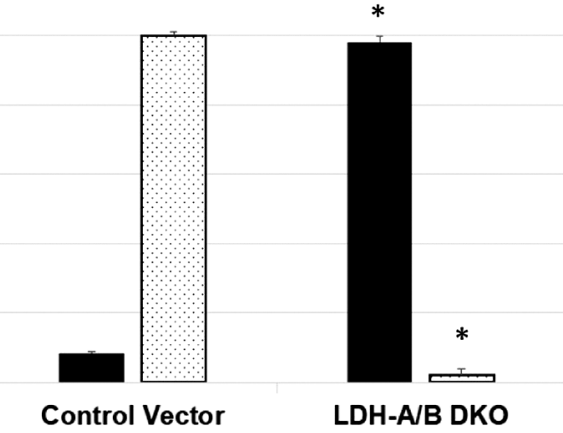

B

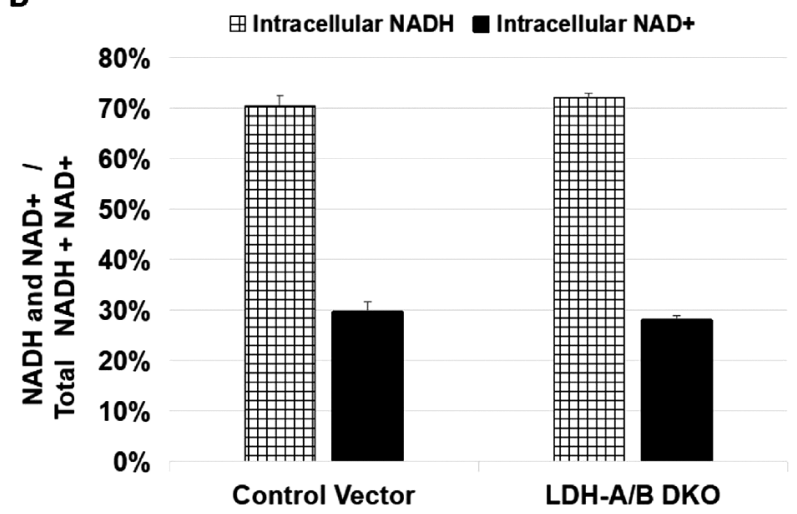

Figure 3. Differential glycolytic profile in the $C V$ vs. $L D H-A / B D K O$ LS174T when cultured in low glucose media. (A) The data are expressed as mean $\pm S E M, n=4$ for glucose consumed relative to media blank (\% media blank control) and lactate produced relative to \% lactate released in the control vector. Significant differences between the vector control and $L D H-A / B$ DKO were determined by a student's t-test, $* p<0.05$. Differential redox in CV vs. LDH-A/B DKO LS174T cells cultured in high glucose media. (B) The data are expressed as mean $\pm S E M, n=4$ for $N A D H$ and NAD+ as relative \% of the total combined NADH+NAD+ concentrations. Significant differences between the vector control and $L D H-A / B$ DKO were determined by student's t-test, $p<0.05, N S$.

$\mathrm{MPP}+$ in the $\mathrm{CV}$ group and 855 DEGs by MPP+ in the LDHA/B - DKO group. Of these changes, MPP+ caused very similar changes in both groups for 79-up-regulated genes and 270 down-regulated ones. The largest DEG reduction for MPP+ in both groups was HIST1H2BM (-9.16 FC, FDR- $p=0.0000621$, Control Vector) and (-136.76 FC, FDR $-p=0.0000011$, LDH-A/B DKO).

Using the String interactive database, we looked at overlapping DEGs in the $\mathrm{CV}$ and the LDH-A/B DKO group evoked by MPP+ on OXPHOS related processes. MPP+ downregulated several mitochondrial-related genes, including
A

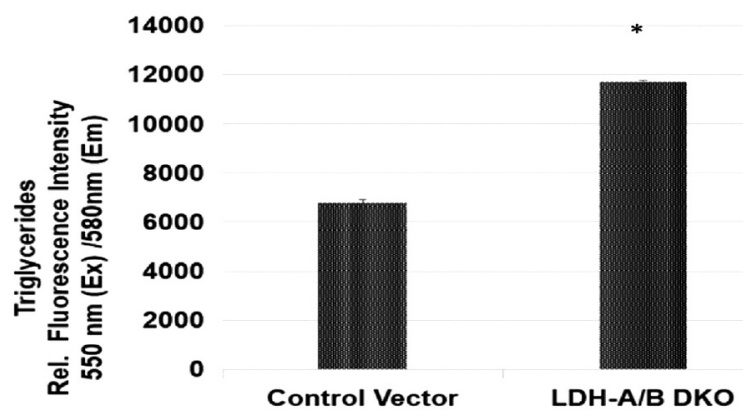

$\mathbf{B}$

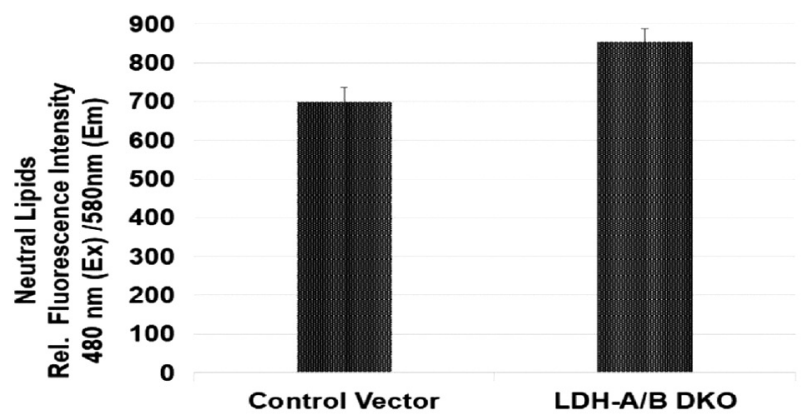

C

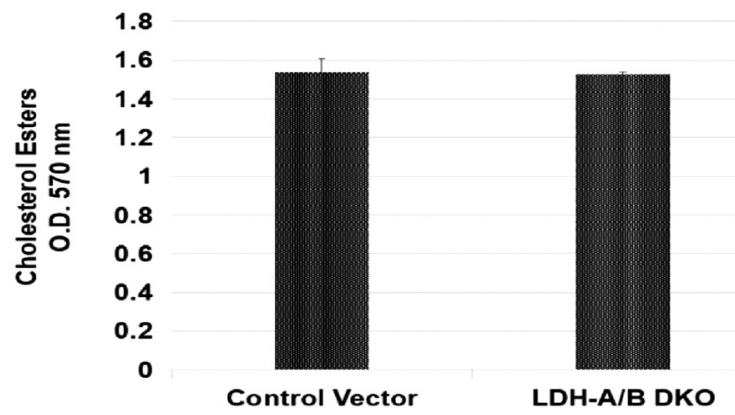

Figure 4. Differential lipid profiles for the $C V$ vs. $L D H-A / B D K O$ LS174T cells cultured in high glucose media. The data are expressed as mean $\pm S E M, n=4$ as relative fluorescence for (A) Neutral Lipids and (B) Triglycerides and optical density for $(C)$ cholesterol esters. Significant differences between the vector control and $L D H-A / B$ DKO were determined by student's $t$-test, ${ }^{*} p<0.05$.

transcripts coding sub-units of NADH dehydrogenase (Complex 1), mitochondrial outer compartment and fatty acid metabolism genes (Figure 6). More specifically, in both groups MPP+ reduced cytochrome b (CTYB), ATPase, class V, type 10A (ATP10A), NADH dehydrogenase, subunit 3 (complex I) (ND3) and NADH dehydrogenase, subunit 6 (complex I) (ND6) (Refer to NIH Gene Expression Omnibus located at: https:// www.ncbi.nlm.nih.gov/geo/query/acc.cgi?acc=GSE149289). 


\section{Control Vector: Control vs. Control + MPP \\ * Control : 3 samples Control + MPP+: 3 samples}

\author{
Filter Criter \\ *Fold change: $>2$ or $<-2$ \\ * P-val: $<0.05$
}

\section{Total number of Genes: $\mathbf{4 8 2 2 6}$}

* Genes Passed Filter Criteria :1738 (3.6\%)

*Up-Regulated: 520

* Down-Regulated: 1218

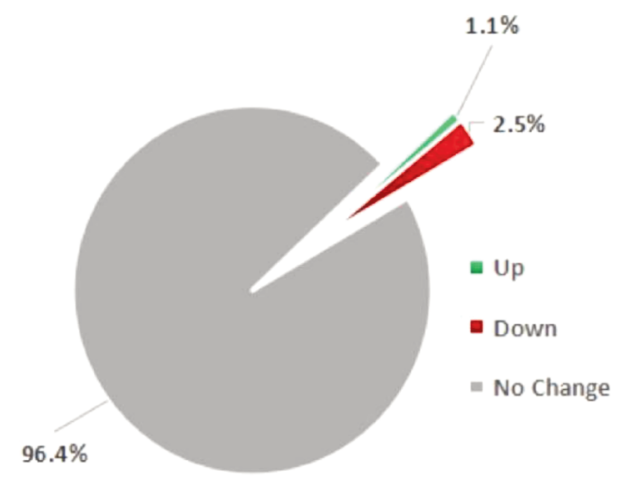

LDH-A/B DKO vs. LDH-A/B DKO + MPP

* LDH-A/B DKO : 3 samples LDH-A/B DKO + MPP+: 3 samples

\author{
Filter Criter \\ *Fold change: $>2$ or $<-2$ \\ * P-val: $<0.05$
}

Total number of Genes: $\mathbf{4 8 2 2 6}$

* Genes Passed Filter Criteria :855 (1.8\%)

*Up-Regulated: 323

* Down-Regulated: 532

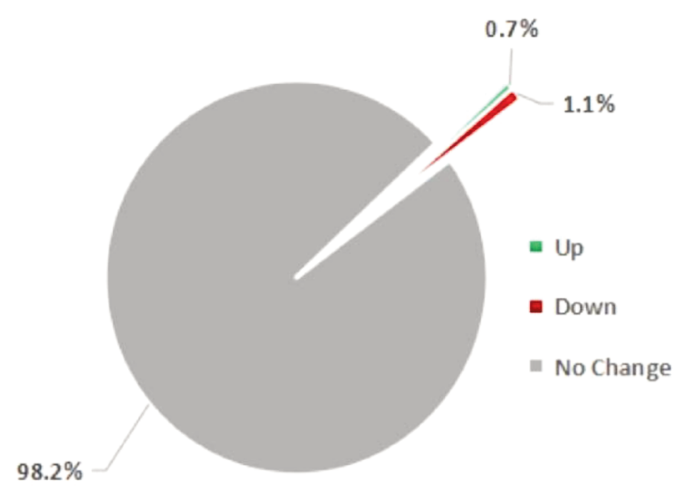

Figure 5. Human transcriptome summary report for $C V$ vs. $C V+M P P+$ and $L D H-A / B D K O v s . L D H-A / B D K O+M P P+$. The summary of differentially expressed genes (DEGs) from the total number of genes evaluated; 48,226 using Affymetrix 2.1 ST Human Arrays. There were 416 overlapping DEGs of the same gene when treated by MPP+ in control vs. LDH-A/B DKOs.

In response to $\mathrm{MPP}+$, the global transcriptome differential expression for both groups $\pm \mathrm{MPP}+$ are shown by the volcano plot summary in Figure $7(\mathrm{CV})$ and Figure $8(\mathrm{LDH}-\mathrm{A} / \mathrm{B}$ DKO). Using the DAVID comprehensive functional annotation bioinformatics array analysis tools, we provide the most significantly impacted biological systems by MPP+ in both groups (CV and LDH-A/B DKO) (Table I). It is evident that in both groups, MPP+ caused a down-regulation of transcripts which are essential for cell division, progression through the cell cycle, DNA replication, DNA strand elongation and excision repair, underscored by large changes in the epigenetic activity (Table I, Annotation cluster 8 and 14).

These changes were also observed using the Affymetrix transcriptome analysis (TAC) Wiki pathway analysis tool describing the effects of MPP+ on the CV (Figure 9) and the LDH-A/B DKO cell line (Figure 10). MPP+ caused significant changes to everything from the origin recognition complexes, minichromosomal maintenance complexes, and genes involved with each of the four phases of the cell cycle (G1, S, G2, and $M)$. With very few up-regulatory DEGS in both groups by $\mathrm{MPP}+$, DAVID analysis tools fall short of providing solid enrichment scores but rather indicate a probability of stressrelated genes (Table II). Refer to the data located in NIH Gene Expression Omnibus at https:/www.ncbi.nlm.nih.gov/geo/ query/acc. cgi?acc=GSE149289.

Next, we provide the unique DEG profiles elicited by MPP+ being specific to only the LDH-A/B DKO cell lines in Table III with ** denoting elements incorporated into the discussion regarding the differential transcriptomes related to glycolysis, the TCA cycle and reducing equivalents shuttled to the mitochondria. A general schematic is presented in Figure 11. These findings provide a basic platform for future analysis into understanding how cancer cells might overcome such dramatic simultaneous insult to both OXPHOS and SLP.

\section{Discussion}

Biological response to hypoxia, anoxia, or mitochondrial impairment in eukaryotes involves a compensatory shift toward anaerobic glycolysis, which sustain ATP through substrate level phosphorylation (SLP), resulting in accumulation of lactic acid. SLP is strictly dependent upon the function of lactic acid 


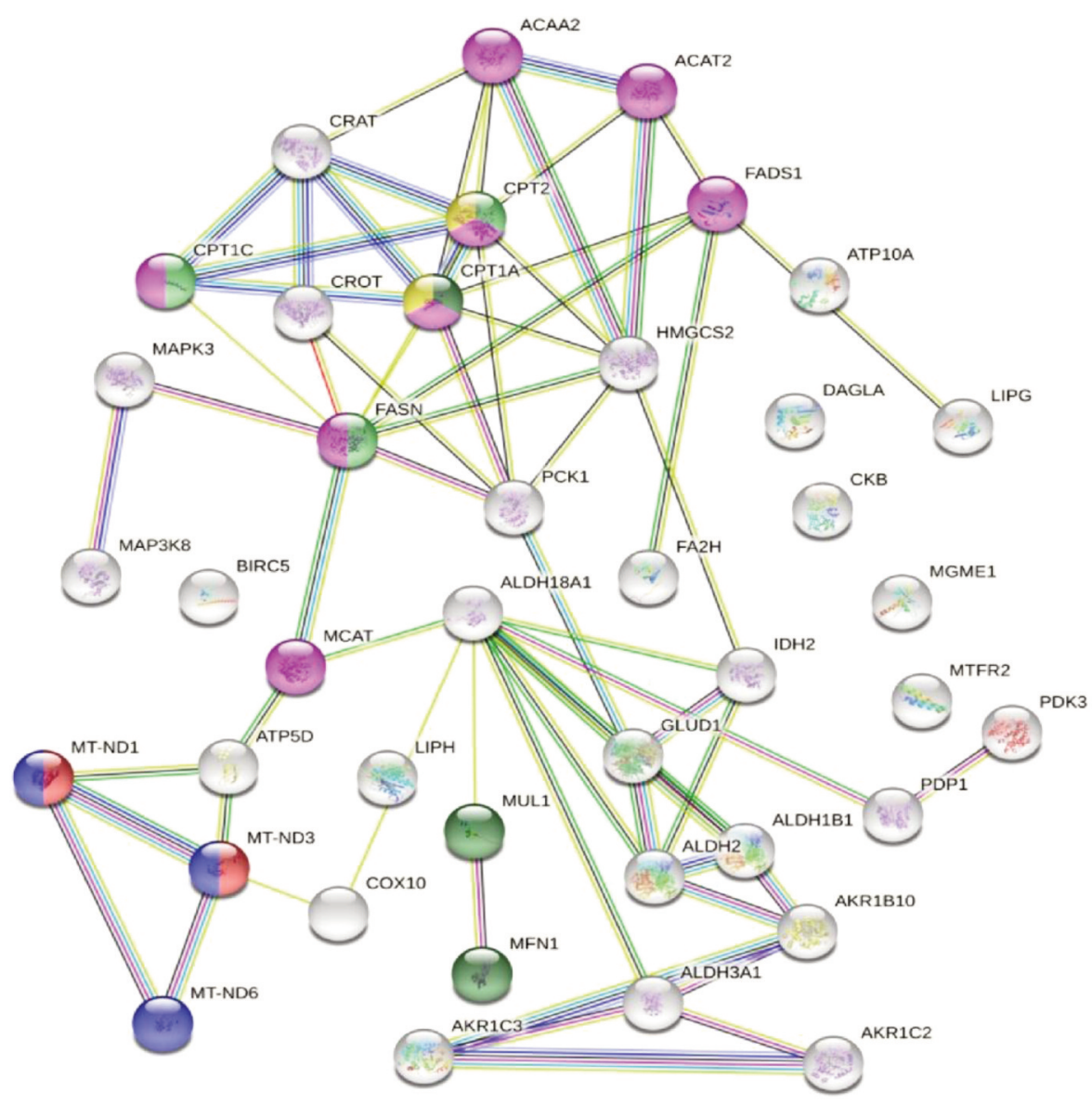

\begin{tabular}{|c|c|c|c|c|c|c|}
\hline ID & Go-Term & Description & $\begin{array}{l}\text { Count in } \\
\text { Network }\end{array}$ & Strength & FDR & Color Code \\
\hline & \multicolumn{6}{|c|}{ Cellular Component (Gene Ontology) } \\
\hline GO-Term & GO:0031307 & Mitochondrial Member (Outer Component) & 3 of 23 & 1.79 & 0.0003 & \\
\hline GO-Term & GO:0005747 & Mitochondrial Complex I (NADH Dehydrogenase) & 2 of 46 & 1.32 & 0.024 & \\
\hline \multirow[t]{2}{*}{ GO-Term } & GO:0070469 & Respiration & 3 of 93 & 1.19 & 0.0065 & \\
\hline & \multicolumn{6}{|c|}{ Local network cluster (STRING) } \\
\hline \multirow[t]{2}{*}{ Cluster } & CL: 21473 & Mitochondrial Member (Outer Component) & 3 of 23 & 1.79 & 0.0005 & \\
\hline & \multicolumn{6}{|c|}{ KEGG Pathways } \\
\hline \multirow[t]{2}{*}{ Pathway } & hsa01212 & Fatty Acid Metabolism & 8 of 48 & 1.9 & $1.86 \mathrm{E}-11$ & \\
\hline & \multicolumn{5}{|c|}{ Reactome Pathways } & \\
\hline Pathway & HSA:200425 & Import of Palmitoyl-CoA into the mitochondrial & 2 of 14 & 1.83 & 0.007 & \\
\hline
\end{tabular}

FDR = False Discovery Rate, Color Code $=$ String Mode Ball Gene Symbol Match

Figure 6. Mitochondrial, energy-related genes altered by MPP+ in both the CV and LDH-A/B DKO sets as determined by the Protein-Protein Interactive String Database Analysis. The data are presented as gene symbol (circular) and color-coded (circular), specifically for mitochondrial related and energy processes listed in the results. White-colored nodes are presented for REDOX and apoptotic related genes.

dehydrogenase (LDH) in order to convert pyruvate to lactic acid to generate oxidized NAD+ to drive ATP production through phosphoglycerate kinase and pyruvate kinase. However, in cancer cells, even in the presence of normoxia or hyperoxia, there is predominant glycolytic activity and lactic acid accumulation, originally believed to involve a defect in mitochondria and referred to as the Warburg effect $(31,32)$. Recently, there has been a paradigm shift due to advances in 


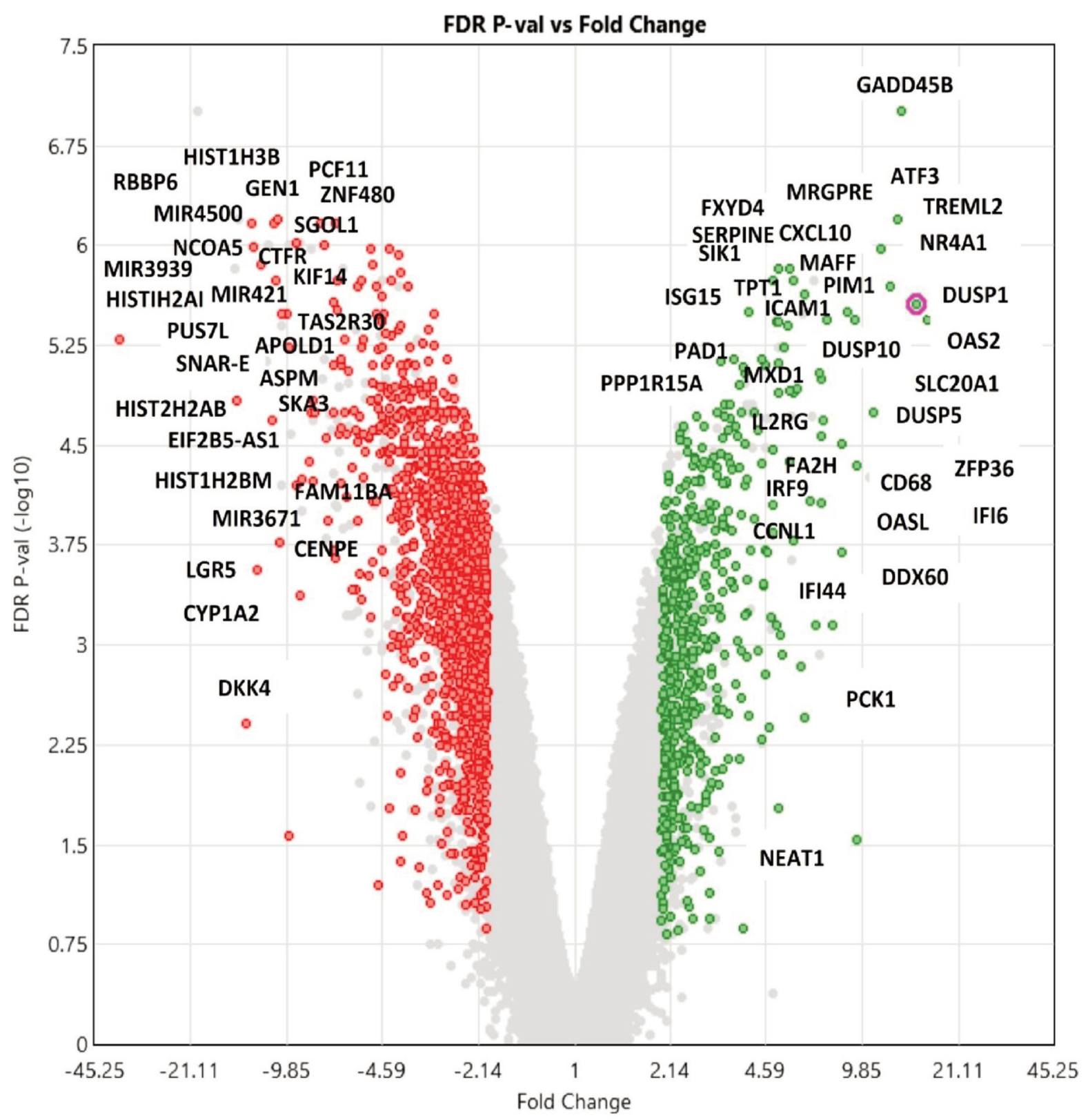

Figure 7. Whole transcriptomic DEG profile of the Control vector LS174T cells \pm MPP+. The data is expressed in a volcano plot providing information on fold change (X-axis) and FDR p-Value (Y-axis). The graph contains select gene symbols for the most highly affected genes.

cancer research. First, the Warburg effect is not necessarily a function of faulty mitochondria, but one of its main purposes is to sustain tumor microenvironment acidity (33), which is paramount to invasive metastasis, chemo resistance and immune escape $(34,35)$. Secondly, while the mitochondrial electron transport chain (ETC) and OXPHOS is required to sustain tumor growth and ATP production when needed $(33,36,37)$, high levels of either oxygen and/or greater mitochondrial biogenesis will drive tumorigenic processes as evidenced by perioperative surgical, experimental models (6-8) and investigation of stem cell metabolism $(9,10)$. While previous therapeutic attempts have involved experimenting with glycolytic inhibitors (38), a fairly new area of anti-cancer therapy now includes deployment of mitochondria-targeted therapeutics, however challenges in using classical inhibitors of OXPHOS are not without counter-indication, as mitochondrial inhibitors have a long history of contributing to degenerative diseases such as Parkinson's or Alzheimer's disease $(39,40)$. 


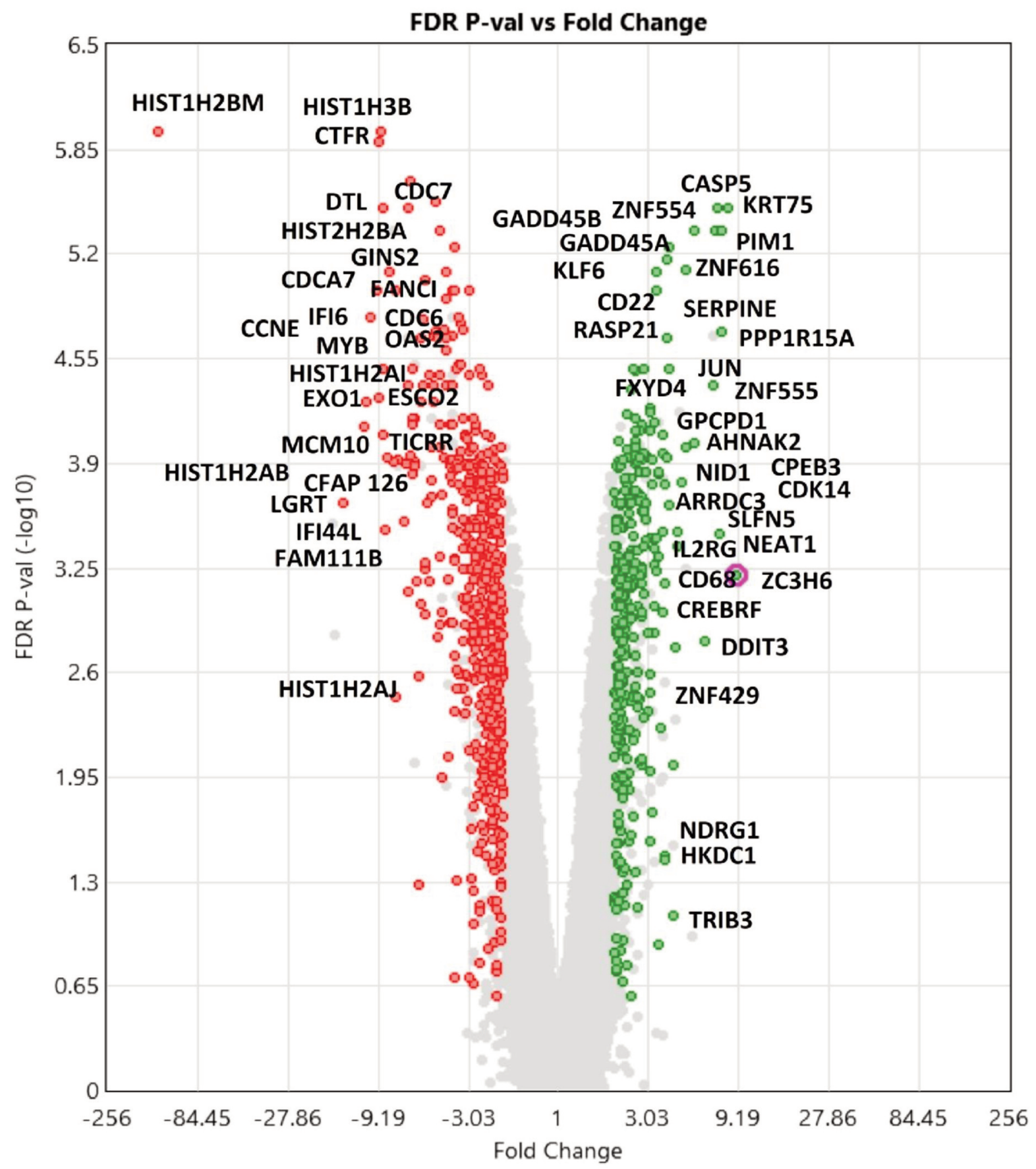

Figure 8. Whole transcriptomic DEG profile of the LDH-A/B DKO LS174T cells $\pm M P P+$. The data is expressed in a volcano plot providing information on fold change (X-axis) and FDR p-Value (Y-axis). The graph contains select gene symbols for the most highly affected genes.

A rationale for the use of mitochondrial inhibitors to treat cancer was instituted by cause-effect linked observation where reduced tumor growth occurred in individuals using various drugs with mitochondrial inhibiting properties such as anesthetics. Several types of anesthetics (complex I,II,III and IV inhibitors), such as propofol, ropivacaine and bupivacaine reduce mitochondrial biogenesis, PGC-1alpha (41-43) and accelerate glycolysis exerting reduced tumor growth and augmented chemotherapeutic efficacy (44-47) similarly, silencing critical OXPHOS related genes such as 
Table I. DAVID functional annotation pathway analysis of down-regulated-DEGs caused by MPP+ when comparing Controls vs. Controls + MPP + and LDH-A/B DKO vs. LDH-A/B DKO + MPP+. The data represents enrichment score, biological classifications, DEG count, $p$-Value, and Benjamin False Discovery p-Value.

\begin{tabular}{|c|c|c|c|c|}
\hline \multirow{2}{*}{$\begin{array}{l}\text { Cluster } \\
\text { Annotation Cluster } 1\end{array}$} & \multirow{2}{*}{$\begin{array}{c}\text { Enrichment score } \\
\text { Enrichment Score: } 38.7\end{array}$} & \multirow{2}{*}{ \#Genes } & \multicolumn{2}{|c|}{ Significance } \\
\hline & & & $p$-Value & Benjamini \\
\hline & Cell cycle \& Mitosis & 78 & $4.10 \mathrm{E}-56$ & $9.30 \mathrm{E}-54$ \\
\hline \multirow[t]{2}{*}{ Annotation Cluster 2} & Enrichment Score: 22.82 & Count & $p$-Value & Benjamini \\
\hline & Chromosome, Chromatid, Centromeres, Kinetochores & 55 & $9.30 \mathrm{E}-42$ & $1.10 \mathrm{E}-39$ \\
\hline \multirow[t]{2}{*}{ Annotation Cluster 3} & Enrichment Score: 22.77 & Count & $p$-Value & Benjamini \\
\hline & DNA Replication, G1/S Transition Mitosis & 29 & $4.80 \mathrm{E}-32$ & $1.80 \mathrm{E}-30$ \\
\hline \multirow[t]{2}{*}{ Annotation Cluster 4} & Enrichment Score: 18.97 & Count & $p$-Value & Benjamini \\
\hline & DNA Damage & 36 & $1.50 \mathrm{E}-22$ & $3.80 \mathrm{E}-21$ \\
\hline \multirow[t]{2}{*}{ Annotation Cluster 5} & Enrichment Score: 6.97 & Count & $p$-Value & Benjamini \\
\hline & ATP Binding & 42 & $3.50 \mathrm{E}-08$ & $3.80 \mathrm{E}-07$ \\
\hline \multirow[t]{2}{*}{ Annotation Cluster 6} & Enrichment Score: 6.69 & Count & $p$-Value & Benjamini \\
\hline & ATPase Domain Binding & 13 & $8.00 \mathrm{E}-08$ & $9.00 \mathrm{E}-06$ \\
\hline \multirow[t]{2}{*}{ Annotation Cluster 7} & Enrichment Score: 6.34 & Count & $p$-Value & Benjamini \\
\hline & Fanconi anemia pathway (DNA repair) & 10 & $3.30 \mathrm{E}-08$ & $7.50 \mathrm{E}-07$ \\
\hline \multirow{4}{*}{ Annotation Cluster 8} & Enrichment Score: 5.46 & Count & $p$-Value & Benjamini \\
\hline & Epigenetics: Chromatin, Methylation, & 18 & $3.10 \mathrm{E}-15$ & $1.90 \mathrm{E}-13$ \\
\hline & Nucleosome Remodeling, Histone Core \& & & & \\
\hline & folds, citrullination, H2A, H3.1, H3.2, H3, & & & \\
\hline \multirow[t]{2}{*}{ Annotation Cluster 9} & Enrichment Score: 5.23 & Count & $p$-Value & Benjamini \\
\hline & DNA Replication/MCM Helicase, MCM Complex & 8 & $2.50 \mathrm{E}-08$ & 8.70E-07 \\
\hline \multirow[t]{2}{*}{ Annotation Cluster 10} & Enrichment Score: 5.13 & Count & $p$-Value & Benjamini \\
\hline & $\begin{array}{l}\text { DNA strand elongation, replication, damage } \\
\text { repair, translation, DNA Polymerase, } \\
\text { nucleotide excision repair }\end{array}$ & 14 & $5.00 \mathrm{E}-16$ & $2.20 \mathrm{E}-14$ \\
\hline \multirow[t]{2}{*}{ Annotation Cluster 11} & Enrichment Score: 4.62 & Count & $p$-Value & Benjamini \\
\hline & $\begin{array}{l}\text { DNA strand replacement, recombination, } \\
\text { reciprocal meiotic recombination, lateral element, } \\
\text { recombinase, double-strand break reprocessing }\end{array}$ & 13 & $1.80 \mathrm{E}-14$ & $1.60 \mathrm{E}-12$ \\
\hline \multirow[t]{2}{*}{ Annotation Cluster 12} & Enrichment Score: 4.26 & Count & $p$-Value & Benjamini \\
\hline & Cyclins, P53 Signaling Pathway & 6 & $1.50 \mathrm{E}-06$ & $5.30 \mathrm{E}-05$ \\
\hline \multirow[t]{2}{*}{ Annotation Cluster 13} & Enrichment Score: 3.67 & Count & $p$-Value & Benjamini \\
\hline & $\begin{array}{l}\text { Microtubule movement, Kinesins-motor } \\
\text { regions, retrograde Golgi to ER }\end{array}$ & 19 & $5.60 \mathrm{E}-09$ & $6.70 \mathrm{E}-08$ \\
\hline \multirow[t]{2}{*}{ Annotation Cluster 14} & Enrichment Score: 2.83 & Count & $p$-Value & Benjamini \\
\hline & $\begin{array}{l}\text { Epigenetics: H4, histone Binding, silencing at } \\
\text { rDNA, TAF, beta catenin-TCF complex assembly }\end{array}$ & 10 & $2.10 \mathrm{E}-08$ & $5.00 \mathrm{E}-07$ \\
\hline \multirow[t]{2}{*}{ Annotation Cluster 15} & Enrichment Score: 2.25 & Count & $p$-Value & Benjamini \\
\hline & HHH2, Helix-hairpin-helix motif, class 2, XPGN & 3 & $8.40 \mathrm{E}-04$ & 4.10E-02 \\
\hline \multirow{2}{*}{ Annotation Cluster 16} & Enrichment Score: 2.09 & Count & $p$-Value & Benjamini \\
\hline & Purine, Pyrimidine, DNA Polymerases & 4 & $4.00 \mathrm{E}-05$ & $3.50 \mathrm{E}-04$ \\
\hline \multirow[t]{2}{*}{ Annotation Cluster 17} & Enrichment Score: 2.08 & Count & $p$-Value & Benjamini \\
\hline & Protein Phosphatase (tyrosine) & 7 & $1.30 \mathrm{E}-05$ & 4.20E-04 \\
\hline
\end{tabular}

S100 calcium-binding protein A4 (S100A4) will reduce OXPHOS, complex I and ATP, accelerate glycolysis and attenuate invasive metastatic tumorigenesis in a threedimensional growth models or in vivo (48). This pattern also extends to cardiac drugs (e.g. atovaquone; complex III inhibitor) (2) and anti-diabetic drugs such as the biguanide metformin or phenformin (complex I inhibitor), which attenuates mitochondrial respiration, amplifies glycolysis and results in reduced tumor growth in diverse models such as lymphoma (49-51). Phenformin has a history of causing lactic acidosis, which was in some cases fatal, justifying removal from the US drug market $(52,53)$. In the case of metformin, lactic acidosis is not as severe and is considered fairly safe (54) with potential drug repurposing application to treat diverse human cancers $(55,56)$. Oddly, in vitro experimental models using cancer cells to investigate the efficacy of metformin + glycolytic inhibitors such as 2-DG, require relatively high concentrations to confer symbiotic effects 


\section{EFFECTS OF MPP+ ON CELL CYCLE IN CONTROL VECTOR}

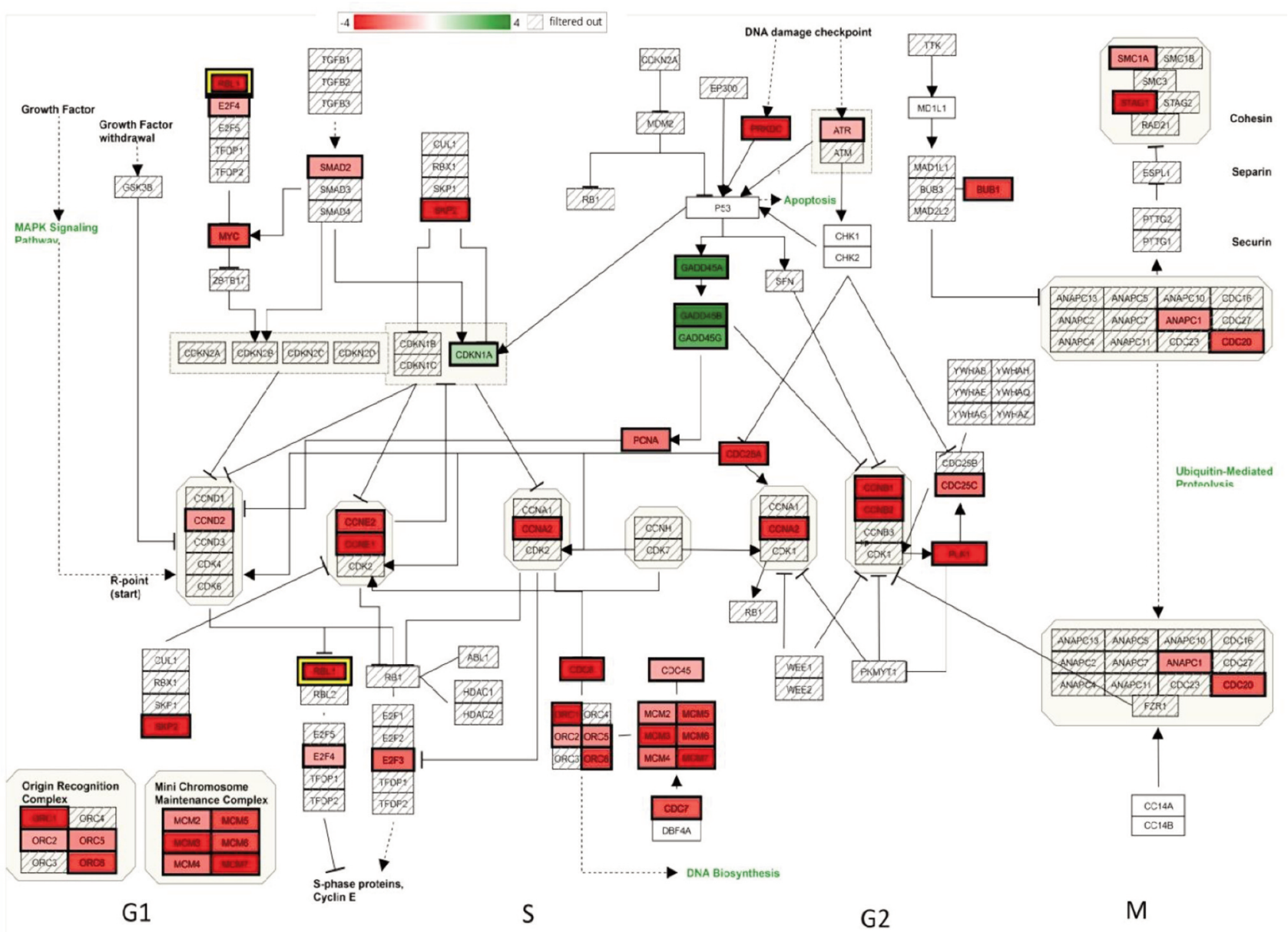

Figure 9. Affymetrix transcriptomic analysis of down-regulated-DEGs caused by MPP+ in Control Vector (Figure 8A) and LDHA/B-DKO (Figure $8 B)$ collectively involved with cell cycle arrest. Green, up-regulated DEG; red, down-regulated genes.

(high $\mathrm{uM}$-low mM) $(49,57,58)$. For this reason, there has been a recent surge in rationale and design of sophisticated conjugated cationic lipophilic mitochondrial carries that carry drugs such as metformin directly to the mitochondria in tumor cells (e.g. Mito-Met10), which can drastically alter the efficacy of a drug such as metformin by approximately 400 fold (59). The use of mitochondrial cationic lipophilic carriers, are central to today's mitochondrial targeting therapies which work by taking advantage of tumor specific depolarized plasma membrane potentials/ acidic $\mathrm{pH}+$ coupled to mitochondria negatively charged or hydrophilic polymerstabilized nano-carries to access the mitochondria. These carrier backed systems include attaching diverse drugs to a cationic lipophilic carrier such as triphenylphosphonium (TPP+) or mitoquinone (Mito-Q) coenzyme Q + TPP+, housing conjugated mitochondrial inhibitors (Complex I-III inhibitors, ATP synthase inhibitors, or uncoupling agents), chemotherapy drugs, antioxidants, some of these have been combined with glycolytic inhibitors such as 2-deoxyglucose (2-DG) $(60,61)(62-64)$. Other cations that can be used as cancer specific theranostic imaging or conjugated to a variety of other moieties including dequalinium (DQA), guanidine, Mito-carboxy proxyl (Mito-CP), pyridinium, 3phenylsulfonylfuroxan, or (E)-4-(1H-indol-3-ylvinyl)-Nmethylpyridinium iodide (F16) which can carry with them a variety of drugs (e.g. chlorambucil, vitamin derivatives, or metformin) $(62,65-68)$ to inhibit tumor growth $(62,69)$.

In the current study, we directly employ the use of MPP+ to inhibit the mitochondria because it a well-known complex I and IV inhibitor, with the capacity to both reduce transcripts that encode mitochondrial enzymes as well as being eliciting kinetic inhibition of cytochrome oxidase (7073). Here we treat colon cancer cells with MPP+ either without the LDH-A/B gene or a control set, the former 


\section{Effects of MPP+ on Cell Cycle in LDH-A/B DKO}

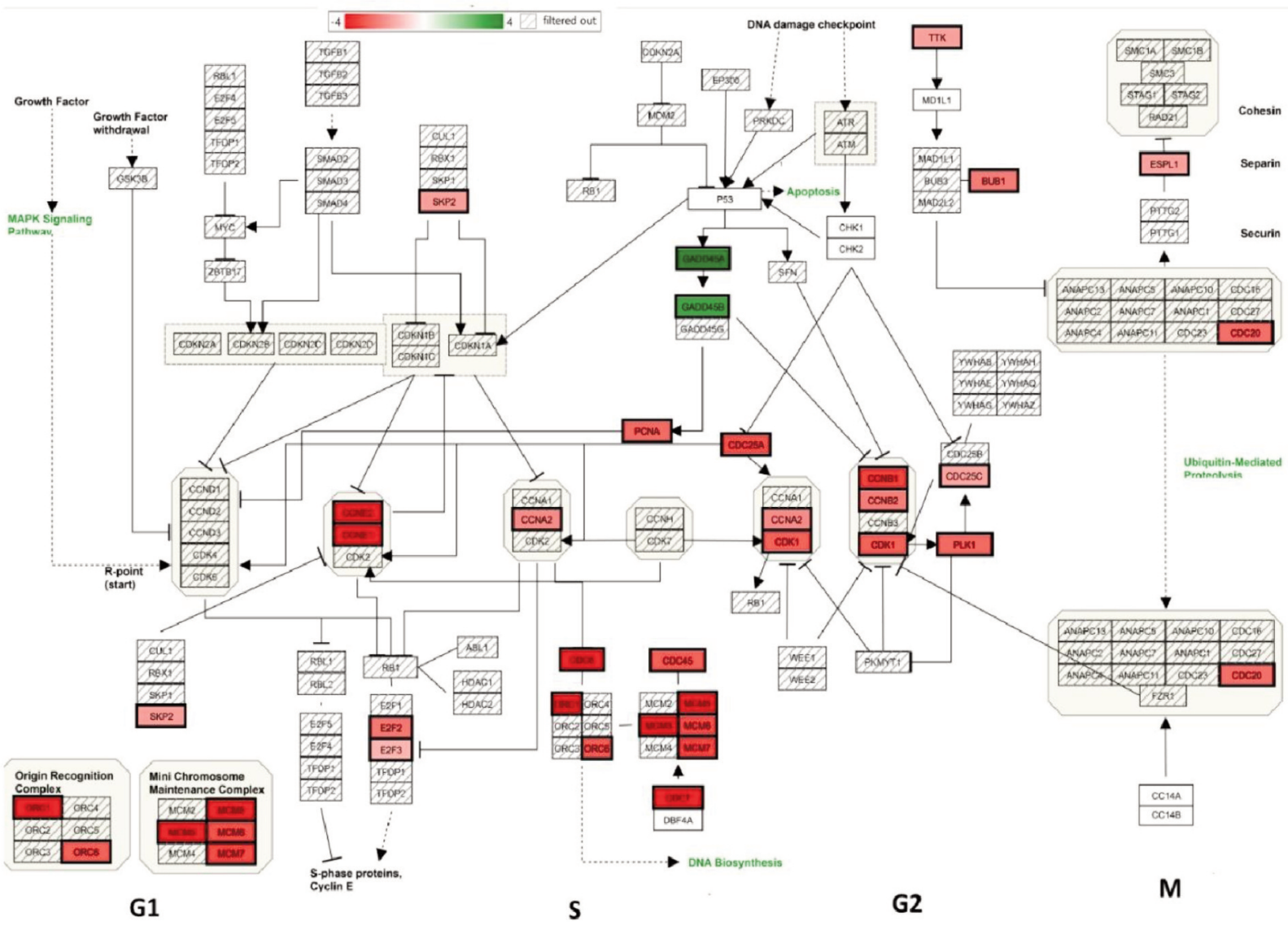

Figure 10. Affymetrix transcriptomic analysis of upregulated DEGs caused by MPP+ when comparing Controls vs. Controls $+M P P+$ and LDH$A / B D K O$ vs. $L D H-A / B D K O+M P P+$. The data represents $F C(p<0.05)$, where DEGs were far greater in controls than $L D H-A / B D K O(b l a c k-$ right) and greater in $L D H-A / B D K O$ than controls on the left (Red).

Table II. DAVID functional annotation pathway analysis of up-regulated DEGs caused by MPP+ when comparing Controls vs. Controls + MPP+ and $L D H-A / B D K O$ vs. $L D H-A / B D K O+M P P+$. The data represents enrichment score, biological classifications, DEG count, $p$-Value, and Benjamin False Discovery p-Value.

\begin{tabular}{|c|c|c|c|c|}
\hline Cluster & Enrichment score & \#Genes & \multicolumn{2}{|c|}{ Significance } \\
\hline Annotation Cluster 1 & $\begin{array}{l}\text { Enrichment Score: } 3.08 \\
\text { Apoptosis \& ER Stress }\end{array}$ & $\begin{array}{c}\text { Count } \\
6\end{array}$ & $\begin{array}{l}p \text {-Value } \\
1.10 \mathrm{E}-05\end{array}$ & $\begin{array}{l}\text { Benjamini } \\
6.40 \mathrm{E}-03\end{array}$ \\
\hline Annotation Cluster 2 & $\begin{array}{c}\text { Enrichment Score: } 1.72 \\
\text { BRLZ, Negative Regulation of Transcription }\end{array}$ & $\begin{array}{c}\text { Count } \\
6\end{array}$ & $\begin{array}{l}p \text {-Value } \\
2.10 \mathrm{E}-06\end{array}$ & $\begin{array}{c}\text { Benjamini } \\
4.20 \mathrm{E}-04\end{array}$ \\
\hline Annotation Cluster 3 & $\begin{array}{c}\text { Enrichment Score: } 1.09 \\
\text { Protein - Tyrosine Phosphatase }\end{array}$ & $\begin{array}{c}\text { Count } \\
3\end{array}$ & $\begin{array}{c}p \text {-Value } \\
2.50 \mathrm{E}-02\end{array}$ & $\begin{array}{l}\text { Benjamini } \\
1.00 \mathrm{E}+00\end{array}$ \\
\hline Annotation Cluster 4 & $\begin{array}{l}\text { Enrichment Score: } 0.86 \\
\text { GTPase Activator }\end{array}$ & $\begin{array}{c}\text { Count } \\
4\end{array}$ & $\begin{array}{l}p \text {-Value } \\
9.30 \mathrm{E}-02\end{array}$ & $\begin{array}{c}\text { Benjamini } \\
1.00 \mathrm{E}+00\end{array}$ \\
\hline
\end{tabular}


Table III. Unique DEGs in the LDH-A/B DKO vs. LDH-A/B DKO + MPP. The data are expressed as Gene symbol, FC, and p-Value.

\begin{tabular}{|c|c|c|c|c|}
\hline Gene Symbol & Description & Fold change & $p$-Value & FDR $p$-Value \\
\hline AGPAT5 & 1-acylglycerol-3-phosphate O-acyltransferase 5 & 2.18 & $1.07 \mathrm{E}-05$ & $8.00 \mathrm{E}-04$ \\
\hline DHCR24 & 24-dehydrocholesterol reductase & -2.14 & $1.17 \mathrm{E}-05$ & $9.00 \mathrm{E}-04$ \\
\hline DHCR7 & 7-dehydrocholesterol reductase & -2.14 & $5.01 \mathrm{E}-05$ & $2.30 \mathrm{E}-03$ \\
\hline ACAT2 & Acetyl-CoA acetyltransferase 2 & -2.56 & $2.44 \mathrm{E}-06$ & $3.00 \mathrm{E}-04$ \\
\hline ACAA2 & Acetyl-CoA acyltransferase 2 & -3.05 & $4.60 \mathrm{E}-07$ & $1.00 \mathrm{E}-04$ \\
\hline ASCL2 & Achaete-scute family bHLH transcription factor 2 & -3.24 & $1.14 \mathrm{E}-05$ & $9.00 \mathrm{E}-04$ \\
\hline ACAD9 & Acyl-CoA dehydrogenase family, member 9 & -2.06 & $1.77 \mathrm{E}-05$ & $1.20 \mathrm{E}-03$ \\
\hline ACADSB & Acyl-CoA dehydrogenase, short/branched chain & -2.23 & $1.43 \mathrm{E}-05$ & $1.00 \mathrm{E}-03$ \\
\hline AHNAK2 & AHNAK nucleoprotein 2 & 5.27 & $2.34 \mathrm{E}-07$ & $9.47 \mathrm{E}-05$ \\
\hline AARS & Alanyl-tRNA synthetase & 3.05 & $5.00 \mathrm{E}-04$ & $1.04 \mathrm{E}-02$ \\
\hline ALDH1B1 & Aldehyde dehydrogenase 1 family, member B1 & -4.63 & $6.25 \mathrm{E}-08$ & 4.07E-05 \\
\hline ALDH18A1 & Aldehyde dehydrogenase 18 family, member A1 & -2.18 & $1.24 \mathrm{E}-05$ & $9.00 \mathrm{E}-04$ \\
\hline ALDH3A1 & Aldehyde dehydrogenase 3 family, member A1 & -2.84 & $5.10 \mathrm{E}-03$ & $5.75 \mathrm{E}-02$ \\
\hline AKR1C3 & Aldo-keto reductase family 1, member $\mathrm{C} 3$ & -2.2 & $5.00 \mathrm{E}-04$ & $1.14 \mathrm{E}-02$ \\
\hline ASB4 & Ankyrin repeat and SOCS box containing 4 & -2.97 & $5.06 \mathrm{E}-08$ & $3.59 \mathrm{E}-05$ \\
\hline ARMC3 & Armadillo repeat containing 3 & -3.61 & $1.00 \mathrm{E}-04$ & $4.30 \mathrm{E}-03$ \\
\hline ARRDC3 & Arrestin domain containing 3 & 4.55 & $8.25 \mathrm{E}-07$ & $2.00 \mathrm{E}-04$ \\
\hline ATP5D & ATP synthase, $\mathrm{H}+$ transporting, mitochondrial $\mathrm{F} 1$ complex, delta subunit & -2.05 & $5.42 \mathrm{E}-06$ & $5.00 \mathrm{E}-04$ \\
\hline BAAT & Bile acid-CoA:amino acid N-acyltransferase & -3.44 & $5.29 \mathrm{E}-07$ & $1.00 \mathrm{E}-04$ \\
\hline CRAT & Carnitine O-acetyltransferase & -2.07 & $2.01 \mathrm{E}-05$ & $1.20 \mathrm{E}-03$ \\
\hline CPT1C & Carnitine palmitoyltransferase $1 \mathrm{C}$ & -2.11 & $5.05 \mathrm{E}-06$ & $5.00 \mathrm{E}-04$ \\
\hline CPT2 & Carnitine palmitoyltransferase 2 & -2.16 & $1.12 \mathrm{E}-06$ & $2.00 \mathrm{E}-04$ \\
\hline CASP5 & Caspase 5 & 6.98 & $6.10 \mathrm{E}-10$ & $3.27 \mathrm{E}-06$ \\
\hline CEMIP & Cell migration inducing protein, hyaluronan binding & -3.02 & $6.25 \mathrm{E}-09$ & $1.08 \mathrm{E}-05$ \\
\hline CRBN & Cereblon & 2.57 & $4.28 \mathrm{E}-08$ & $3.33 \mathrm{E}-05$ \\
\hline CFAP126 & Cilia and flagella associated protein 126 & -7.14 & $4.06 \mathrm{E}-07$ & $1.00 \mathrm{E}-04$ \\
\hline $\mathrm{CKB}$ & Creatine kinase, brain & -2.95 & $1.59 \mathrm{E}-05$ & $1.10 \mathrm{E}-03$ \\
\hline CDK1 & Cyclin-dependent kinase 1 & -3.15 & $2.18 \mathrm{E}-06$ & $3.00 \mathrm{E}-04$ \\
\hline CPEB3 & Cytoplasmic polyadenylation element binding protein 3 & 3.06 & $3.13 \mathrm{E}-06$ & $4.00 \mathrm{E}-04$ \\
\hline DAGLA & Diacylglycerol lipase, alpha & 2.16 & $1.50 \mathrm{E}-03$ & $2.46 \mathrm{E}-02$ \\
\hline ERN1 & Endoplasmic reticulum to nucleus signaling 1 & 3.03 & $2.47 \mathrm{E}-05$ & $1.40 \mathrm{E}-03$ \\
\hline FAM171B & Family with sequence similarity 171 , member B & -3.56 & $1.92 \mathrm{E}-09$ & $5.78 \mathrm{E}-06$ \\
\hline FAM216A & Family with sequence similarity 216, member A & -2.56 & 4.92E-08 & $3.55 \mathrm{E}-05$ \\
\hline FADS1 & Fatty acid desaturase 1 & -2.25 & $4.34 \mathrm{E}-06$ & $5.00 \mathrm{E}-04$ \\
\hline FASN & Fatty acid synthase & -2.16 & $2.75 \mathrm{E}-05$ & $1.50 \mathrm{E}-03$ \\
\hline GMNN & Geminin, DNA replication inhibitor & -3.06 & $1.29 \mathrm{E}-06$ & $2.00 \mathrm{E}-04$ \\
\hline GPAT3 & Glycerol-3-phosphate acyltransferase 3 & 2.08 & $2.43 \mathrm{E}-05$ & $1.40 \mathrm{E}-03$ \\
\hline GMPR & Guanosine monophosphate reductase & -4.18 & $5.00 \mathrm{E}-04$ & $1.14 \mathrm{E}-02$ \\
\hline HKDC1 & Hexokinase domain containing 1 & 3.72 & $2.40 \mathrm{E}-03$ & $3.41 \mathrm{E}-02$ \\
\hline HIST2H2AA4; HIST2H2AA3 & Histone cluster 2, H2aa4; histone cluster 2, H2aa3 & -3.67 & $1.69 \mathrm{E}-08$ & $2.02 \mathrm{E}-05$ \\
\hline HIST2H2BB; HIST2H3PS2 & Histone cluster 2, $\mathrm{H} 2 \mathrm{bb}$ (pseudogene); histone cluster 2, H3, pseudogene 2 & -4.6 & $6.06 \mathrm{E}-08$ & $4.07 \mathrm{E}-05$ \\
\hline ID3 & Inhibitor of DNA binding 3, dominant negative helix-loop-helix protein & -2.74 & $1.73 \mathrm{E}-07$ & $7.92 \mathrm{E}-05$ \\
\hline IFITM3 & Interferon induced transmembrane protein 3 & -3.63 & $5.73 \mathrm{E}-09$ & $1.08 \mathrm{E}-05$ \\
\hline $\mathrm{IDH} 2$ & Isocitrate dehydrogenase 2 (NADP+), mitochondrial & -2.61 & $9.89 \mathrm{E}-07$ & $2.00 \mathrm{E}-04$ \\
\hline KRT75 & Keratin 75 , type II & 8.05 & $4.52 \mathrm{E}-10$ & $3.22 \mathrm{E}-06$ \\
\hline LEMD1; BLACAT1 & $\begin{array}{l}\text { LEM domain containing } 1 \text {; bladder cancer associated } \\
\text { transcript } 1 \text { (non-protein coding) }\end{array}$ & 3.11 & $1.77 \mathrm{E}-07$ & $7.94 \mathrm{E}-05$ \\
\hline LINC01207 & Long intergenic non-protein coding RNA 1207 & 3.8 & 3.53E-07 & $1.00 \mathrm{E}-04$ \\
\hline MME & Membrane metallo-endopeptidase & -3.25 & $6.04 \mathrm{E}-06$ & $6.00 \mathrm{E}-04$ \\
\hline MT1H & Metallothionein $1 \mathrm{H}$ & -3.18 & $6.01 \mathrm{E}-05$ & $2.60 \mathrm{E}-03$ \\
\hline $\begin{array}{l}\text { MIR1244-1; MIR1244-2; } \\
\text { MIR1244-3; MIR1244-4 }\end{array}$ & $\begin{array}{l}\text { MicroRNA 1244-1; microRNA 1244-2; microRNA 1244-3; } \\
\text { microRNA } 1244-4\end{array}$ & -3.74 & $6.75 \mathrm{E}-07$ & $2.00 \mathrm{E}-04$ \\
\hline MSN & Moesin & 2.53 & $3.89 \mathrm{E}-08$ & $3.29 \mathrm{E}-05$ \\
\hline NEDD4L & $\begin{array}{l}\text { Neural precursor cell expressed, developmentally } \\
\text { down-regulated 4-like, E3 ubiquitin protein ligase }\end{array}$ & 3.31 & $5.95 \mathrm{E}-09$ & $1.08 \mathrm{E}-05$ \\
\hline NTS & Neurotensin & -5.78 & $8.02 \mathrm{E}-06$ & $7.00 \mathrm{E}-04$ \\
\hline NID1 & Nidogen 1 & 4.77 & $2.58 \mathrm{E}-07$ & $9.92 \mathrm{E}-05$ \\
\hline
\end{tabular}


Table III. Continued

\begin{tabular}{|c|c|c|c|c|}
\hline Gene Symbol & Description & Fold change & $p$-Value & FDR $p$-Value \\
\hline NDRG1 & $\mathrm{N}$-myc downstream regulated 1 & 3.64 & $2.60 \mathrm{E}-03$ & $3.63 \mathrm{E}-02$ \\
\hline PLCB4 & Phospholipase $\mathrm{C}$, beta 4 & -3.09 & $8.76 \mathrm{E}-07$ & $2.00 \mathrm{E}-04$ \\
\hline PEA15 & Phosphoprotein enriched in astrocytes 15 & 2.34 & $1.10 \mathrm{E}-07$ & $6.18 \mathrm{E}-05$ \\
\hline PRTFDC1 & Phosphoribosyl transferase domain containing 1 & -3.17 & $1.97 \mathrm{E}-07$ & $8.43 \mathrm{E}-05$ \\
\hline PIWIL1 & Piwi-like RNA-mediated gene silencing 1 & -4.49 & $1.52 \mathrm{E}-08$ & $1.94 \mathrm{E}-05$ \\
\hline PLLP & Plasmolipin & -3.48 & 4.16E-08 & $3.29 \mathrm{E}-05$ \\
\hline PDK3 & Pyruvate dehydrogenase kinase, isozyme 3 & -2.09 & 2.00E-04 & $5.90 \mathrm{E}-03$ \\
\hline PDP1 & Pyruvate dehyrogenase phosphatase catalytic subunit 1 & 2.54 & $1.78 \mathrm{E}-07$ & 7.94E-05 \\
\hline REEP6 & Receptor accessory protein 6 & -4.56 & $3.11 \mathrm{E}-10$ & $3.00 \mathrm{E}-06$ \\
\hline RNASEL & Ribonuclease L (2,5-oligoisoadenylate synthetase-dependent) & 3.42 & 4.45E-06 & $5.00 \mathrm{E}-04$ \\
\hline RRM2 & Ribonucleotide reductase M2 & -6.31 & $5.15 \mathrm{E}-10$ & $3.22 \mathrm{E}-06$ \\
\hline RNF144A & Ring finger protein $144 \mathrm{~A}$ & 3.68 & $8.72 \mathrm{E}-07$ & $2.00 \mathrm{E}-04$ \\
\hline RNU5D-1 & RNA, U5D small nuclear 1 & -10.92 & $1.60 \mathrm{E}-07$ & $7.50 \mathrm{E}-05$ \\
\hline RNU5F-1 & RNA, U5F small nuclear 1 & -6.38 & 9.97E-06 & $8.00 \mathrm{E}-04$ \\
\hline SAMHD1 & SAM domain and HD domain 1 & -3.97 & 7.19E-09 & $1.20 \mathrm{E}-05$ \\
\hline SLFN5 & Schlafen family member 5 & 7.24 & $2.81 \mathrm{E}-06$ & $3.00 \mathrm{E}-04$ \\
\hline SNORA11; MAGED2 & Small nucleolar RNA, H/ACA box 11; MAGE family member D2 & 4.17 & $3.40 \mathrm{E}-05$ & $1.80 \mathrm{E}-03$ \\
\hline SLC12A2 & Solute carrier family 12 (sodium/potassium/chloride transporter), member 2 & -4.32 & $9.46 \mathrm{E}-10$ & $4.52 \mathrm{E}-06$ \\
\hline SLC22A 15 & Solute carrier family 22, member 15 & 4.07 & $4.00 \mathrm{E}-04$ & $9.40 \mathrm{E}-03$ \\
\hline SLC25A37 & Solute carrier family 25 (mitochondrial iron transporter), member 37 & 2.54 & $1.24 \mathrm{E}-07$ & $6.62 \mathrm{E}-05$ \\
\hline SRM & Spermidine synthase & -3.02 & $6.31 \mathrm{E}-06$ & $6.00 \mathrm{E}-04$ \\
\hline SOAT1 & sterol O-acyltransferase 1 & -2.87 & $6.49 \mathrm{E}-06$ & $6.00 \mathrm{E}-04$ \\
\hline SOD2 & Superoxide dismutase 2 , mitochondrial & -2.25 & $1.30 \mathrm{E}-03$ & $2.25 \mathrm{E}-02$ \\
\hline TESC & Tescalcin & -3 & $3.12 \mathrm{E}-07$ & $1.00 \mathrm{E}-04$ \\
\hline TK1 & Thymidine kinase 1 , soluble & -3.12 & $2.96 \mathrm{E}-06$ & $4.00 \mathrm{E}-04$ \\
\hline TIMELESS & Timeless circadian clock & -4.11 & 1.38E-08 & $1.86 \mathrm{E}-05$ \\
\hline TMEM9B-AS1 & TMEM9B antisense RNA 1 & 3.6 & $2.71 \mathrm{E}-06$ & $3.00 \mathrm{E}-04$ \\
\hline TMEM71; LRRC6 & Transmembrane protein 71; leucine rich repeat containing 6 & 3.11 & $1.07 \mathrm{E}-07$ & $6.07 \mathrm{E}-05$ \\
\hline UBE2T & Ubiquitin conjugating enzyme E2T & -3.74 & $5.18 \mathrm{E}-09$ & $1.08 \mathrm{E}-05$ \\
\hline USP18 & Ubiquitin specific peptidase 18 & -3 & $9.39 \mathrm{E}-07$ & $2.00 \mathrm{E}-04$ \\
\hline $\mathrm{XDH}$ & Xanthine dehydrogenase & 3.25 & $1.36 \mathrm{E}-07$ & $6.92 \mathrm{E}-05$ \\
\hline $\mathrm{ZC} 3 \mathrm{H} 6$ & Zinc finger $\mathrm{CCCH}$-type containing 6 & 3.33 & $6.59 \mathrm{E}-06$ & $6.00 \mathrm{E}-04$ \\
\hline ZNF25 & Zinc finger protein 25 & 3.22 & 5.63E-06 & $5.00 \mathrm{E}-04$ \\
\hline ZNF555 & Zinc finger protein 555 & 6.76 & $6.40 \mathrm{E}-08$ & 4.07E-05 \\
\hline
\end{tabular}

having no capacity to produce lactic acid or drive the alternative ATP SLP pathway. We expected to see complete energy collapse in the LDH-A/B DKO, as reported by others combining mitochondrial inhibitors with glycolytic inhibitors such as DG this was not the case $(70,74-76)$. Keep in mind, this is a unique model, where glycolysis is still functioning to the point of pyruvic acid, so in the true sense, the LDH$\mathrm{A} / \mathrm{BDKO}$ is not a full glycolytic inhibitor but does effectively shut down the required pyruvate to lactate conversion sustain the anaerobic production of ATP through SLP. The data from this study show an unexpected resistance to the toxin in the LDH-A/B DKO, which requires further explanation.

The data in this work establish efficacy of MPP+ to inhibit mitochondrial function, both biologically through suppressive respiration and an observed transcriptional loss of OXPHOS of complex I; NADH dehydrogenase, subunits 3 , and 6 and complex III (cytochrome b). Moreover, the data in this work support our previous study in that the LDHA/BDKO cell line triggered a metabolic response with heightened OXPHOS capacity (15). The baseline respiratory differential may have contributed to a resistance to MPP+ either by necessitating a higher required concentration of $\mathrm{MPP}+$ to elicit damage, or possibly by extruding the drug equipped with high capacity ATPase multi-drug resistance pumps, as there is a clear relationship between higher OXPHOS stem cell metabolism, chemo-resistance, enhanced expression of ATP binding cassette multi-drug resistance pumps and poor clinical outcomes (77-79).

Some of the changes that accompany this resistance are reflected in the transcriptome when analyzing the differential between $\mathrm{CV}$ vs. CV + MPP+ and LDH-A/B DKO vs. LDH$\mathrm{A} / \mathrm{B} \mathrm{DKO}+\mathrm{MPP}+$, such as heightened ATP binding cassette subfamily $\mathrm{C}$ member 3 (ABCC3) multi-drug resistance pump and a differential in the flow of intermediates from pyruvate (glycolysis) to Acetyl-CoA (TCA) or vice versa. MPP+ in 


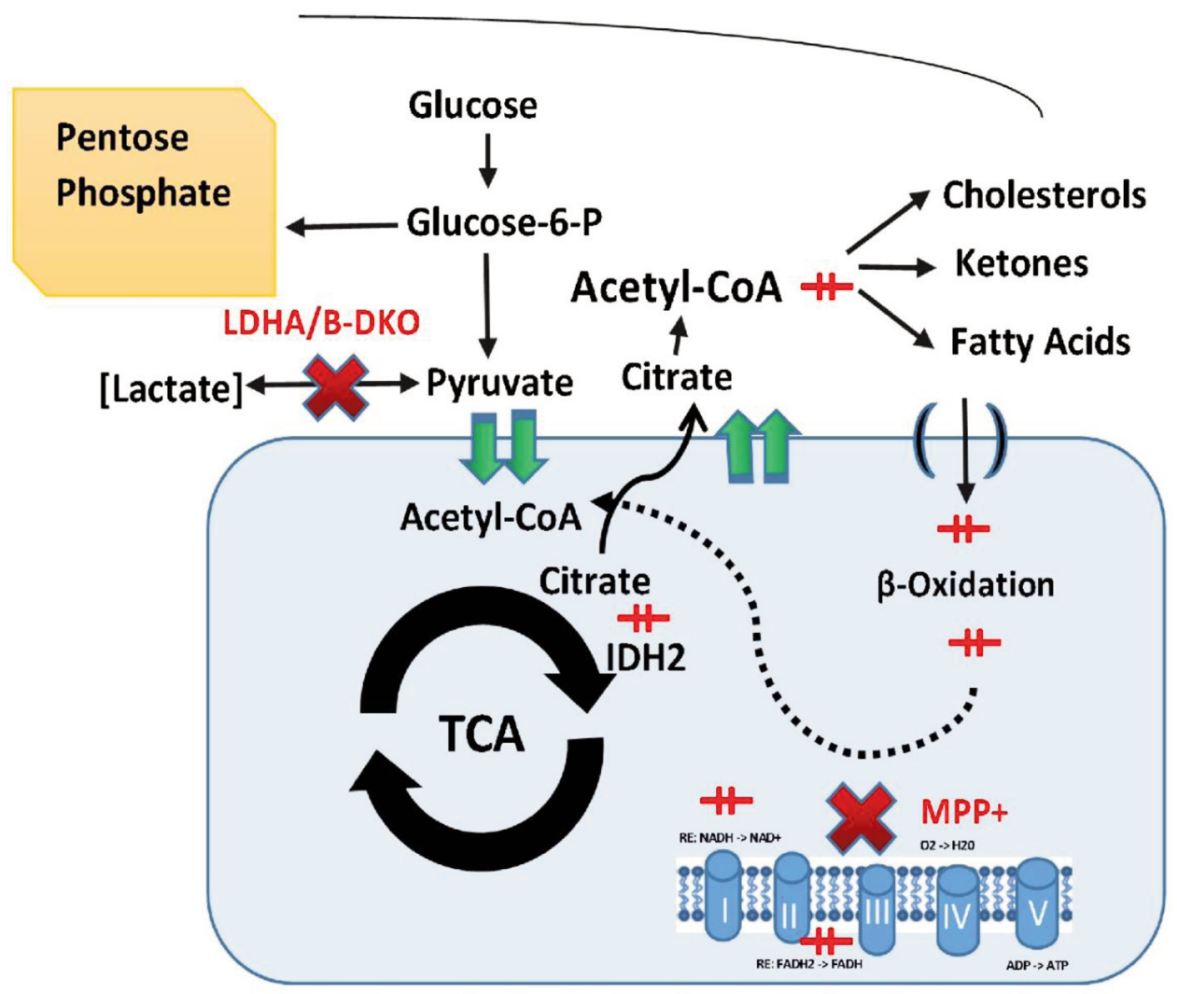

Figure 11. Effects of MPP + in the LDH-A/B DKO cell line. In brief, SLP was compromised by genetic editing of LDH-A/B which blocked production of lactic acid. Chemical challenge to the mitochondria was established using MPP+, effective in attenuating cell respiration and transcriptionally Complex I-V related elements. In the $L D H-A / B D K O$, we see an elevation in transcripts that allow greater flow of pyruvate to the mitochondria and conversion to acetyl-CoA through the pyruvate dehydrogenase complex. There was a pull back down-regulation on inhibitory kinase controls (PDK3) and an up-regulation on forward phosphatase controls (PDP1). The transcriptome showed a down-regulation of iso-citrate dehydrogenase (mitochondrial) required for the tricarboxylic acid (TCA) cycle and enzymes involved with the transport and oxidation of fatty acids: entry of (CPT1C, $C P T 2)$, initial steps in (ACAD9, ACADSB) and final steps required for the B-oxidation spiral (ACAA 2). Lower electron transport chain activity, coincided with lower expression of genes (TCA and fatty acid oxidation) which would generate equivalents (NADH and FADH2), no longer being accepted to generate an electrochemical gradient for ATP production. In addition, acetyl-CoA which is the central carbon currency to fuel energy related processes is also met with a down-regulation of its route through biosynthetic processes including: down-regulated transcripts required for the initiation step of cholesteroll ketone synthesis (ACAT2), the final step of cholesterol synthesis (DHCR 7,DHCR 24) and fatty acid synthesis (FAS).

the $\mathrm{CV}$ resulted in a unique (CV set only) elevation of phosphoenolpyruvate carboxykinase 1 (PKC1), indicative of a response to nutrient deprivation (80) with capacity to redirect carbons from oxaloacetate back into glycolysis to carry out gluconeogenesis. In contrast, the LDH-A/B DKO exposed to MPP+ responded with up-regulation of positive regulator of pyruvate dehydrogenase $(\mathrm{PDH}), \mathrm{PDH}$ phosphatase catalytic subunit 1 (PDP1) with a downregulation of negative $\mathrm{PDH}$ feedback; $\mathrm{PDH}$ kinase, isozyme 3 (PDK3), effect that would push pyruvate to enter the mitochondria, and its conversion to acetyl-CoA. While the LDH-A/B DKO MPP+ treatment group show greater pyruvate to Acetyl-CoA production while there is no conversion of pyruvate to lactic acid, the transcriptome suggests a pooling or accumulation of Acetyl-CoA, since these changes coincide with a reduction in transcripts that code for proteins which enable Acetyl-CoA to be used to drive biosynthetic processes (fatty acid, cholesterol and ketone synthesis).

Examples of these include specific losses in the LDH-A/B $\mathrm{DKO} \mathrm{MPP}+$ group (not in the $\mathrm{CV}+\mathrm{MPP}+$ group), including down-regulation of 1) acyl-CoA dehydrogenase (ACAD9, ACADSB) (initial steps in the fatty acid $\beta$-oxidation pathway) 2) acetyl-CoA acyltransferase 2 (ACAA2) (final steps of the fatty acid beta-oxidation pathway) 3), carnitine palmitoyltransferase (CPT1C, CPT2) (entry of fatty acids into the mitochondria) and 4) isocitrate dehydrogenase (mitochondrial) iso-citrate dehydrogenase 2 (IDH2) which would be required for acetyl-CoA metabolism to drive the TCA cycle. These changes are logically and biochemical sound since a hampered ETC by MPP+ would abate proton shuttling. Therefore, losses in enzymes that drive TCA and 
FA beta-oxidation pathways would also be reduced since the mitochondria no longer accept reducing equivalents (NADH and FADH2) from these pathways to generate an electrochemical gradient for ATP production (9).

The pooling of acetyl-CoA seems to be a unique central aspect in the LDH-A/B DKOs + MPP+ (not present in the $\mathrm{CV}$ vs. $\mathrm{CV}+\mathrm{MPP}+$ ), as there is also a loss of transcripts that encode proteins required to carry out anabolic substrate use of acetyl-CoA to produce cholesterols, fatty acids, and ketones. These include losses to 1) acetyl-CoA acetyltransferase 2) (ACAT2) (the first enzyme in the cholesterol and ketone synthesis pathway which is required to convert two molecules of acetyl-CoA to acetoacetyl-CoA), 2) the final step for cholesterol biosynthesis 24dehydrocholesterol reductase, 7 dehydrocholesterol reductase (DHCR $7 \& 24$ ) and 3) reduction of fatty acid synthase (FAS) needed to carry out condensation reactions from acetyl-CoA and malonyl-CoA and a corresponding loss to fatty acid desaturase 1 (which catalyzes the removal of two hydrogen atoms from a fatty acid, creating a carbon/carbon double bond). These changes coincided with an increase in glycerol3-phosphate (GPAT3) O-acyltransferase which catalyzes the chemical reaction where by acyl-CoA + sn-glycerol 3phosphate is converted to $\mathrm{CoA}+1$-acyl-sn-glycerol 3phosphate required for the organization of phospholipids to sustain biological membrane structures. Acetyl-CoA is the central carbon currency of energy metabolism. It is synthesized from pyruvate in mitochondria, enters into the TCA cycle for conversion to citric acid cycle (citrate synthase), and excess citrate is exported to the cytoplasm by a mitochondrial citrate carrier, where it is reconverted back to acetyl-CoA by ATP-citrate lyase (ACLY) then available for fatty acid, ketone, cholesterol synthesis or acetylation reactions that involve both protein and epigenetic cellular function including histone and chromatin remodeling, which controls transcription of mRNA $(81,82)$. The central functional role of ACLY in driving lipid catabolic tumorigenic processes is the rationale behind the development of inhibitors (e.g., hydroxycitrate, bempedoic acid) in oncology research $(83,84)$. Clearly, acetyl-CoA has a central role in cancer metabolism and also essential to carrying out epigenetic histone modifications/ lysine acetylation (85). Future studies will be required to examine how acetyl-CoA is being utilized in the absence of a functional glycolytic pathway, why it is accruing and how it is being used.

The transcriptome data also reflects the importance of epigenetic changes elicited by MPP+ in both CV and LDHA/B DKOs, evidenced by the sheer number of downregulated histone cluster transcripts as well as the massive bidirectional DEGs in non-protein coding microRNA and long-intergenic transcripts. MPP+ also evoked changes in a number of METTL transcripts, which are believed to contribute to nucleoside modifications in diverse types of
RNA and DNA $(86,87)$, however very little is known on these particular epigenetic modifications.

$\mathrm{MPP}+$ and cell cycle. Other than a loss of OXPHOS by MPP+ as anticipated $(88,89)$ the most significant effect to both groups was a loss of transcripts otherwise required for cell cycle. In both groups we the MPP+ mediated down-regulation of cell cycle genes (CDC20, CDC25A, CDC25C, CDC45, CDC6, CDC 7), cell cycle associated genes (CDCA2, CDCA3, CDCA7 and CDCA8), cyclins (cyclin A2, B1, B2, D, D2, E1, E2, F, L1), cyclin-dependent kinases (CDK1, CDK13, CDK14) and marker of proliferation Ki-67 (MIK67). The effects of $\mathrm{MPP}+$ on both cell lines also resulted in down-regulation of DNA replicative processes including the following: minichromosome maintenance complex components (MCMs 2, 3, $4,5,6,7,8,9,10)$ origin recognition complex subunits (ORCs $1,2,5,6)$, kinesin family member genes (KIFs $11,14,15,18 \mathrm{~A}$, 20A, 20B, 23, 4A) centromere proteins (CENPE E, F, H, I, J, $\mathrm{K}, \mathrm{M}, \mathrm{N}, \mathrm{O}, \mathrm{P}, \mathrm{Q}, \mathrm{U}, \mathrm{W})$ and centrosomal proteins of $\mathrm{kDa}(128$ $\mathrm{kDa}, 135 \mathrm{kDa}, 152 \mathrm{kDa}, 162 \mathrm{kDa}, 192 \mathrm{kDa}, 19 \mathrm{kDa}, 295 \mathrm{kDa}$, $55 \mathrm{kDa}, 76 \mathrm{kDa}, 78 \mathrm{kDa}, 83 \mathrm{kDa}$ and $97 \mathrm{kDa}$ ). Down-regulation also extended to loss of transcripts required replicative DNA processes including; DNA polymerases (POLs A1, A2, D2, E2, Q, D4), DNA primases (PRIMs 1 and 2), DNA repair transcripts (DNA crosslink repair genes: DCLREs 1A,1B and 1C), DNA replication helicase/nuclease gene 2i; GINS complex subunits (Psf1 homolog) (GINS 1, 2, 3 and 4); Fanconi anemia complementation group (FANC A, B, C, D2, I, L and M); spindle and kinetochore associated complex subunits (SKA1,3) and topoisomerases (TOPs 2A, 2B, 2C). These findings are in alignment with others showing the effects of MPP+ in vitro in exerting cytostatic effects, secondary to cell death initiated by glucose depletion as a result of accelerated glycolysis $(88,90)$. Whatever the consequence, there is no doubt that MPP+ caused a significant amount of stress on both cell lines, reflected by upregulation of DNA-damage-inducible, alpha (CADD45A) beta (GADD45B) gamma (GADD45H), commonly the aftermath of strain associated with the loss of cell cycle progression (91) particularly inability to pass the G2-M phase (92-94). Refer to the data located in NIH Gene Expression Omnibus at https://www.ncbi.nlm.nih.gov/geo/query/acc.cgi? acc=GSE149289.

\section{Conclusion}

The findings from this study suggest a complex metabolic survival response to a specific mitochondrial toxin (MPP+) in colon cancer cells that lack LDH-A/B transcripts and the related functional SLP glycolytic anaerobic ATP energy yielding pathway. While this study provides a framework for further analysis, cancer cells without LDH may shift toward aerobic OXPHOS creating counter indication when using mitochondrial targeting drugs, which may necessitate higher concentration. 


\section{Availability of Data and Material}

The dataset has been deposited to NIH Gene Expression Omnibus located at https://www.ncbi.nlm.nih.gov/geo/query/acc.cgi?acc $=$ GSE149289.

\section{Conflicts of Interest}

The Authors declare that they have no conflicts of interest.

\section{Authors' Contributions}

NM conducted studies on basic cell metabolic profiles. EM assisted with these studies and carried out microarray work. RB was involved with mechanistic troubleshooting and study design and KS oversaw and guided this project.

\section{Acknowledgments}

This research was supported by the National Institute of Minority Health and Health Disparities of the National Institutes of Health through Grant Number U54 MD007582 and Grant Number P20 MD006738. We are very grateful for the work of Dr. J Pouyssegur, Dr. S. Cassim, and Dr. M Zdralevic from the University Cote d'Azur, IRCAN, CNRS, Centre A. Lacassagne, Nice, France and Department of Medical Biology, Centre Scientifique de Monaco, Monaco and their generosity in establishing and contributing these cell lines.

\section{References}

1 Zam W, Ahmed I and Yousef H: Warburg effects on cancer cells survival: the role of sugar starvation in cancer therapy. Curr Clin Pharmacol, 2020. PMID: 32282309. DOI: $10.2174 / 157488$ 4715666200413121756

2 Bayley JP and Devilee P: Warburg tumours and the mechanisms of mitochondrial tumour suppressor genes. Barking up the right tree? Curr Opin Genet Dev 20(3): 324-329, 2010. PMID: 20304625. DOI: $10.1016 /$ j.gde.2010.02.008

3 Zhao B, Luo J, Yu T, Zhou L, Lv H and Shang P: Anticancer mechanisms of metformin: A review of the current evidence. Life Sci 254: 117717, 2020. PMID: 32339541. DOI: 10.1016/ j.lfs .2020 .117717

4 Oshima N, Ishida R, Kishimoto S, Beebe K, Brender JR, Yamamoto K, Urban D, Rai G, Johnson MS, Benavides G, Squadrito GL, Crooks D, Jackson J, Joshi A, Mott BT, Shrimp JH, Moses MA, Lee MJ, Yuno A, Lee TD, Hu X, Anderson T, Kusewitt D, Hathaway HH, Jadhav A, Picard D, Trepel JB, Mitchell JB, Stott GM, Moore W, Simeonov A, Sklar LA, Norenberg JP, Linehan WM, Maloney DJ, Dang CV, Waterson AG, Hall M, Darley-Usmar VM, Krishna MC and Neckers LM: Dynamic imaging of LDH inhibition in tumors reveals rapid in vivo metabolic rewiring and vulnerability to combination therapy. Cell Rep 30(6): 1798-1810.e4, 2020. PMID: 32049011. DOI: 10.1016/j.celrep.2020.01.039

5 Zhou Y, Tao P, Wang M, Xu P, Lu W, Lei P and You Q: Development of novel human lactate dehydrogenase A inhibitors: High-throughput screening, synthesis, and biological evaluations. Eur J Med Chem 177: 105-115, 2019. PMID: 31129449. DOI: 10.1016/j.ejmech.2019.05.033
6 Kim B, Jung JW, Jung J, Han Y, Suh DH, Kim HS, Dhanasekaran DN and Song YS: PGC1 $\alpha$ induced by reactive oxygen species contributes to chemoresistance of ovarian cancer cells. Oncotarget 8(36): 60299-60311, 2017. PMID: 28947972. DOI: 10.18632 /oncotarget.19140

7 Praharaj PP, Patro BS and Bhutia SK: Dysregulation of mitophagy and mitochondrial homeostasis in cancer stem cells: Novel mechanism for anti-cancer stem cell-targeted cancer therapy. $\mathrm{Br} \mathrm{J}$ Pharmacol, 2021. PMID: 33527371. DOI: 10.1111/bph.15401

8 Praharaj PP, Panigrahi DP, Bhol CS, Patra S, Mishra SR, Mahapatra KK, Behera BP, Singh A, Patil S and Bhutia SK: Mitochondrial rewiring through mitophagy and mitochondrial biogenesis in cancer stem cells: A potential target for anti-CSC cancer therapy. Cancer Lett 498: 217-228, 2021. PMID: 33186655. DOI: 10.1016/j.canlet.2020.10.036

9 Grasso D, Zampieri LX, Capelôa T, Van de Velde JA and Sonveaux P: Mitochondria in cancer. Cell Stress 4(6): 114-146, 2020. PMID: 32548570. DOI: $10.15698 /$ cst2020.06.221

10 Wei Z, Jia J, Heng G, Xu H, Shan J, Wang G, Liu C, Xia J, Zhou H, Wu M, Yang Z, Wang M, Xiong Z, Huang H, Liu L and Qian C: Sirtuin-1/Mitochondrial ribosomal protein S5 axis enhances the metabolic flexibility of liver cancer stem cells. Hepatology 70(4): 1197-1213, 2019. PMID: 30901096. DOI: 10.1002/hep.30622

11 Mack N, Mazzio EA, Bauer D, Flores-Rozas H and Soliman KF: Stable shRNA silencing of lactate dehydrogenase A (LDHA) in human MDA-MB-231 breast cancer cells fails to alter lactic acid production, glycolytic activity, ATP or survival. Anticancer Res 37(3): 1205-1212, 2017. PMID: 28314283. DOI: 10.21873/ anticanres. 11435

12 Deiab S, Mazzio E, Messeha S, Mack N and Soliman KF: Highthroughput screening to identify plant derived human LDH-A inhibitors. European J Med Plants 3(4): 603-615, 2013. PMID: 24478981. DOI: 10.9734/ejmp/2013/5995

13 Deiab S, Mazzio E, Eyunni S, McTier O, Mateeva N, Elshami F and Soliman KF: 1,2,3,4,6-Penta-O-galloylglucose within galla chinensis inhibits human LDH-A and attenuates cell proliferation in MDA-MB-231 breast cancer cells. Evid Based Complement Alternat Med 2015: 276946, 2015. PMID: 25918543. DOI: $10.1155 / 2015 / 276946$

14 Ždralević M, Brand A, Di Ianni L, Dettmer K, Reinders J, Singer K, Peter K, Schnell A, Bruss C, Decking SM, Koehl G, FelipeAbrio B, Durivault J, Bayer P, Evangelista M, O'Brien T, Oefner PJ, Renner K, Pouysségur J and Kreutz M: Double genetic disruption of lactate dehydrogenases $\mathrm{A}$ and $\mathrm{B}$ is required to ablate the "Warburg effect" restricting tumor growth to oxidative metabolism. J Biol Chem 293(41): 15947-15961, 2018. PMID: 30158244. DOI: $10.1074 /$ jbc.RA118.004180

15 Mazzio E, Badisa R, Mack N, Cassim S, Zdralevic M, Pouyssegur $\mathrm{J}$ and Soliman KFA: Whole-transcriptome analysis of fully viable energy efficient glycolytic-null cancer cells established by double genetic knockout of lactate dehydrogenase A/B or glucose-6phosphate isomerase. Cancer Genomics Proteomics 17(5): 469497, 2020. PMID: 32859627. DOI: 10.21873/cgp.20205

$16 \mathrm{Yu}$ D, Liu C and Guo L: Mitochondrial metabolism and cancer metastasis. Ann Transl Med 8(14): 904, 2020. PMID: 32793748. DOI: $10.21037 / \mathrm{atm} .2020 .03 .42$

17 Yoshida GJ: Beyond the Warburg Effect: N-Myc Contributes to metabolic reprogramming in cancer cells. Front Oncol 10: 791, 2020. PMID: 32547946. DOI: 10.3389/fonc.2020.00791 
18 Oliveira GL, Coelho AR, Marques R and Oliveira PJ: Cancer cell metabolism: Rewiring the mitochondrial hub. Biochim Biophys Acta Mol Basis Dis 1867(2): 166016, 2021. PMID: 33246010. DOI: $10.1016 /$ j.bbadis. 2020.166016

19 McCann E, O'Sullivan J and Marcone S: Targeting cancer-cell mitochondria and metabolism to improve radiotherapy response. Transl Oncol 14(1): 100905, 2021. PMID: 33069104. DOI: 10.1016/j.tranon.2020.100905

20 Sica V, Bravo-San Pedro JM, Stoll G and Kroemer G: Oxidative phosphorylation as a potential therapeutic target for cancer therapy. Int J Cancer 146(1): 10-17, 2020. PMID: 31396957. DOI: $10.1002 / \mathrm{ijc} .32616$

21 Varela-López A, Vera-Ramírez L, Giampieri F, Navarro-Hortal MD, Forbes-Hernández TY, Battino $\mathrm{M}$ and Quiles JL: The central role of mitochondria in the relationship between dietary lipids and cancer progression. Semin Cancer Biol : , 2021. PMID: 33434641. DOI: 10.1016/j.semcancer.2021.01.001

22 Nagarajan SR, Butler LM and Hoy AJ: The diversity and breadth of cancer cell fatty acid metabolism. Cancer Metab 9(1): 2, 2021. PMID: 33413672. DOI: 10.1186/s40170-020-00237-2

23 Reyes-Castellanos G, Masoud R and Carrier A: Mitochondrial metabolism in PDAC: From better knowledge to new targeting strategies. Biomedicines 8(8), 2020. PMID: 32756381. DOI: 10.3390/biomedicines 8080270

24 Vasan K, Werner M and Chandel NS: Mitochondrial metabolism as a target for cancer therapy. Cell Metab 32(3): 341-352, 2020. PMID: 32668195. DOI: 10.1016/j.cmet.2020.06.019

25 Sica V, Bravo-San Pedro JM, Izzo V, Pol J, Pierredon S, Enot D, Durand S, Bossut N, Chery A, Souquere S, Pierron G, Vartholomaiou E, Zamzami N, Soussi T, Sauvat A, Mondragón L, Kepp O, Galluzzi L, Martinou JC, Hess-Stumpp H, Ziegelbauer K, Kroemer G and Maiuri MC: Lethal poisoning of cancer cells by respiratory chain inhibition plus Dimethyl $\alpha$ Ketoglutarate. Cell Rep 27(3): 820-834.e9, 2019. PMID: 30995479. DOI: 10.1016/j.celrep.2019.03.058

26 McMillian MK, Li L, Parker JB, Patel L, Zhong Z, Gunnett JW, Powers WJ and Johnson MD: An improved resazurin-based cytotoxicity assay for hepatic cells. Cell Biol Toxicol 18(3): 157173, 2002. PMID: 12083422. DOI: 10.1023/a:1015559603643

27 Szklarczyk D, Franceschini A, Kuhn M, Simonovic M, Roth A, Minguez P, Doerks T, Stark M, Muller J, Bork P, Jensen LJ and von Mering C: The STRING database in 2011: functional interaction networks of proteins, globally integrated and scored. Nucleic Acids Res 39(Database issue): D561-D568, 2011. PMID: 21045058. DOI: 10.1093/nar/gkq973

28 Szklarczyk D, Gable AL, Nastou KC, Lyon D, Kirsch R, Pyysalo S, Doncheva NT, Legeay M, Fang T, Bork P, Jensen LJ and von Mering C: The STRING database in 2021: customizable protein-protein networks, and functional characterization of user-uploaded gene/measurement sets. Nucleic Acids Res 49(D1): D605-D612, 2021. PMID: 33237311. DOI: $10.1093 / \mathrm{nar} / \mathrm{gkaa} 1074$

29 Huang DW, Sherman BT, Tan Q, Collins JR, Alvord WG, Roayaei J, Stephens R, Baseler MW, Lane HC and Lempicki RA: The DAVID Gene Functional Classification Tool: a novel biological module-centric algorithm to functionally analyze large gene lists. Genome Biol 8(9): R183, 2007. PMID: 17784955. DOI: $10.1186 / \mathrm{gb}-2007-8-9-\mathrm{r} 183$

30 Mazzio EA, Smith B and Soliman KF: Evaluation of endogenous acidic metabolic products associated with carbohydrate metabolism in tumor cells. Cell Biol Toxicol 26(3): 177-188, 2010. PMID: 19784859. DOI: 10.1007/s10565-009-9138-6

31 Bao X, Zhang J, Huang G, Yan J, Xu C, Dou Z, Sun C and Zhang H: The crosstalk between HIFs and mitochondrial dysfunctions in cancer development. Cell Death Dis 12(2): 215, 2021. PMID: 33637686. DOI: 10.1038/s41419-021-03505-1

32 Cuezva JM, Krajewska M, de Heredia ML, Krajewski S, Santamaría G, Kim H, Zapata JM, Marusawa H, Chamorro M and Reed JC: The bioenergetic signature of cancer: a marker of tumor progression. Cancer Res 62(22): 6674-6681, 2002. PMID: 12438266

33 Mazzio EA, Boukli N, Rivera N and Soliman KF: Pericellular $\mathrm{pH}$ homeostasis is a primary function of the Warburg effect: inversion of metabolic systems to control lactate steady state in tumor cells. Cancer Sci 103(3): 422-432, 2012. PMID: 22320183. DOI: $10.1111 / j .1349-7006.2012 .02206 . x$

34 Burgdorf S, Porubsky S, Marx A and Popovic ZV: Cancer acidity and hypertonicity contribute to dysfunction of tumorassociated dendritic cells: Potential impact on antigen crosspresentation machinery. Cancers (Basel) 12(9), 2020. PMID: 32847079. DOI: $10.3390 /$ cancers 12092403

35 Lebelo MT, Joubert AM and Visagie MH: Warburg effect and its role in tumourigenesis. Arch Pharm Res 42(10): 833-847, 2019. PMID: 31473944. DOI: 10.1007/s12272-019-01185-2

36 Hamaguchi R, Ito T, Narui R, Morikawa H, Uemoto S and Wada $\mathrm{H}$ : Effects of alkalization therapy on chemotherapy outcomes in advanced pancreatic cancer: A retrospective case-control study. In Vivo 34(5): 2623-2629, 2020. PMID: 32871792. DOI: 10.21873/invivo. 12080

37 Ando H, Eshima $\mathrm{K}$ and Ishida T: Neutralization of acidic tumor microenvironment (TME) with daily oral dosing of sodium potassium citrate $(\mathrm{K} / \mathrm{Na}$ Citrate) increases therapeutic effect of anti-cancer agent in pancreatic cancer xenograft mice model. Biol Pharm Bull 44(2): 266-270, 2021. PMID: 33518679. DOI: 10.1248/bpb.b20-00825

38 Abdel-Wahab AF, Mahmoud W and Al-Harizy RM: Targeting glucose metabolism to suppress cancer progression: prospective of anti-glycolytic cancer therapy. Pharmacol Res 150: 104511, 2019. PMID: 31678210. DOI: 10.1016/j.phrs.2019.104511

39 Onyango IG, Khan SM and Bennett JP Jr: Mitochondria in the pathophysiology of Alzheimer's and Parkinson's diseases. Front Biosci (Landmark Ed) 22: 854-872, 2017. PMID: 27814651. DOI: $10.2741 / 4521$

40 McKnight S and Hack N: Toxin-Induced parkinsonism. Neurol Clin 38(4): 853-865, 2020. PMID: 33040865. DOI: 10.1016/ j.ncl.2020.08.003

$41 \mathrm{Xu} \mathrm{Y,} \mathrm{Pan} \mathrm{S,} \mathrm{Jiang} \mathrm{W,} \mathrm{Xue} \mathrm{F} \mathrm{and} \mathrm{Zhu} \mathrm{X:} \mathrm{Effects} \mathrm{of} \mathrm{propofol} \mathrm{on}$ the development of cancer in humans. Cell Prolif 53(8): e12867, 2020. PMID: 32596964. DOI: 10.1111/cpr.12867

42 Lotz C, Stumpner J and Smul TM: Sevoflurane as opposed to propofol anesthesia preserves mitochondrial function and alleviates myocardial ischemia/reperfusion injury. Biomed Pharmacother 129: 110417, 2020. PMID: 32574972. DOI: 10.1016/j.biopha.2020.110417

43 Qin J, Li Y and Wang K: Propofol induces impairment of mitochondrial biogenesis through inhibiting the expression of peroxisome proliferator-activated receptor- $\gamma$ coactivator- $1 \alpha$. J Cell Biochem 120(10): 18288-18297, 2019. PMID: 31190345. DOI: $10.1002 /$ jcb. 29138

44 Sumi C, Okamoto A, Tanaka H, Nishi K, Kusunoki M, Shoji T, Uba T, Matsuo Y, Adachi T, Hayashi JI, Takenaga K and Hirota 
K: Propofol induces a metabolic switch to glycolysis and cell death in a mitochondrial electron transport chain-dependent manner. PLoS One 13(2): e0192796, 2018. PMID: 29447230. DOI: 10.1371/journal.pone.0192796

45 Zhu G, Zhang L, Dan J and Zhu Q: Differential effects and mechanisms of local anesthetics on esophageal carcinoma cell migration, growth, survival and chemosensitivity. BMC Anesthesiol 20(1): 126, 2020. PMID: 32450791. DOI: 10.1186/s12871-020-01039-1

46 Zhu Q, Zhu G, Xu W, Dan J, Xia R and Liu W: Bupivacaine inhibits angiogenesis through oxidative stress-dependent inhibition of Akt/mTOR and activation of AMPK. Fundam Clin Pharmacol 34(5): 581-590, 2020. PMID: 32145095. DOI: 10.1111/fcp.12554

47 Yang J, Li G, Bao K, Liu W, Zhang Y and Ting W: Ropivacaine inhibits tumor angiogenesis via sodium-channel-independent mitochondrial dysfunction and oxidative stress. J Bioenerg Biomembr 51(3): 231-238, 2019. PMID: 30847691. DOI: 10.1007/s10863-019-09793-9

48 Liu L, Qi L, Knifley T, Piecoro DW, Rychahou P, Liu J, Mitov MI, Martin J, Wang C, Wu J, Weiss HL, Butterfield DA, Evers BM, O'Connor KL and Chen M: S100A4 alters metabolism and promotes invasion of lung cancer cells by up-regulating mitochondrial complex I protein NDUFS2. J Biol Chem 294(18): 7516-7527, 2019. PMID: 30885944 . DOI: $10.1074 /$ jbc.RA118.004365

49 Fontaine E: Metformin-induced mitochondrial complex I inhibition: Facts, uncertainties, and consequences. Front Endocrinol (Lausanne) 9: 753, 2018. PMID: 30619086. DOI: 10.3389/fendo.2018.00753

50 Izreig S, Gariepy A, Kaymak I, Bridges HR, Donayo AO, Bridon G, DeCamp LM, Kitchen-Goosen SM, Avizonis D, Sheldon RD, Laister RC, Minden MD, Johnson NA, Duchaine TF, Rudoltz MS, Yoo S, Pollak MN, Williams KS and Jones RG: Repression of LKB1 by miR-17 92 sensitizes MYC-dependent lymphoma to biguanide treatment. Cell Rep Med 1(2): 100014, 2020. PMID: 32478334. DOI: 10.1016/j.xcrm.2020.100014

51 Pecinová A, Brázdová A, Drahota Z, Houštěk J and Mráček T: Mitochondrial targets of metformin-Are they physiologically relevant? Biofactors 45(5): 703-711, 2019. PMID: 31343786. DOI: $10.1002 /$ biof.1548

52 Mengis CL: Lactic acid acidemia and phenformin. Rocky Mt Med J 61: 39-41, 1964. PMID: 14221484

53 Kwong SC and Brubacher J: Phenformin and lactic acidosis: a case report and review. J Emerg Med 16(6): 881-886, 1998. PMID: 9848705. DOI: 10.1016/s0736-4679(98)00103-6

54 Wang GS and Hoyte C: Review of biguanide (Metformin) toxicity. J Intensive Care Med 34(11-12): 863-876, 2019. PMID: 30126348. DOI: $10.1177 / 0885066618793385$

55 Jaidee R, Kongpetch S, Senggunprai L, Prawan A, Kukongviriyapan U and Kukongviriyapan V: Phenformin inhibits proliferation, invasion, and angiogenesis of cholangiocarcinoma cells via AMPK-mTOR and HIF-1A pathways. Naunyn Schmiedebergs Arch Pharmacol 393(9): 1681-1690, 2020. PMID: 32383028. DOI: $10.1007 / \mathrm{s} 00210-020-01885-3$

56 Pistoni M, Tondelli G, Gallo C, Torricelli F, Maresca A, Carelli V, Ciarrocchi A and Dallaglio K: Exploring metabolic reprogramming in melanoma via acquired resistance to the oxidative phosphorylation inhibitor phenformin. Melanoma Res 30(1): 1-13, 2020. PMID: 31116160. DOI: 10.1097/CMR.0000000000000624

57 Mathews Samuel S, Satheesh NJ, Ghosh S, Büsselberg D, Majeed $\mathrm{Y}$, Ding $\mathrm{H}$ and Triggle CR: Treatment with a combination of metformin and 2-Deoxyglucose upregulates Thrombospondin-1 in microvascular endothelial cells: Implications in Anti-Angiogenic Cancer Therapy. Cancers (Basel) 11(11), 2019. PMID: 31698699. DOI: $10.3390 /$ cancers 11111737

58 Wokoun U, Hellriegel M, Emons G and Gründker C: Co-treatment of breast cancer cells with pharmacologic doses of 2-deoxy-Dglucose and metformin: Starving tumors. Oncol Rep 37(4): 24182424, 2017. PMID: 28350075. DOI: 10.3892/or.2017.5491

59 Cheng G, Zielonka J, Ouari O, Lopez M, McAllister D, Boyle K, Barrios CS, Weber JJ, Johnson BD, Hardy M, Dwinell MB and Kalyanaraman B: Mitochondria-targeted analogues of metformin exhibit enhanced antiproliferative and radiosensitizing effects in pancreatic cancer cells. Cancer Res 76(13): 3904-3915, 2016. PMID: 27216187. DOI: 10.1158/0008-5472.CAN-15-2534

60 Kafkova A and Trnka J: Mitochondria-targeted compounds in the treatment of cancer. Neoplasma 67(3): 450-460, 2020. PMID: 32122145. DOI: 10.4149/neo_2020_190725N671

61 Wang J, Li J, Xiao Y, Fu B and Qin Z: TPP-based mitocans: a potent strategy for anticancer drug design. RSC Med Chem 11(8): 858-875, 2020. PMID: 33479681. DOI: 10.1039/ c9md00572b

62 Battogtokh G, Choi YS, Kang DS, Park SJ, Shim MS, Huh KM, Cho YY, Lee JY, Lee HS and Kang HC: Mitochondria-targeting drug conjugates for cytotoxic, anti-oxidizing and sensing purposes: current strategies and future perspectives. Acta Pharm Sin B $8(6)$ : 862-880, 2018. PMID: 30505656. DOI: 10.1016/j.apsb.2018. 05.006

63 Huang M, Myers CR, Wang Y and You M: Mitochondria as a novel target for cancer chemoprevention: Emergence of mitochondrial targeting agents. Cancer Prev Res (Phila) : , 2020. PMID: 33303695. DOI: 10.1158/1940-6207.CAPR-20-0425

64 Dilip A, Cheng G, Joseph J, Kunnimalaiyaan S, Kalyanaraman B, Kunnimalaiyaan M and Gamblin TC: Mitochondria-targeted antioxidant and glycolysis inhibition: synergistic therapy in hepatocellular carcinoma. Anticancer Drugs 24(9): 881-888, 2013. PMID: 23872912. DOI: 10.1097/CAD.0b013e32836442c6

65 Millard M, Gallagher JD, Olenyuk BZ and Neamati N: A selective mitochondrial-targeted chlorambucil with remarkable cytotoxicity in breast and pancreatic cancers. J Med Chem 56(22): 9170-9179, 2013. PMID: 24147900. DOI: 10.1021/jm4012438

66 Singh G and Moorehead R: Mitochondria as a target for combination cancer-chemotherapy. Int J Oncol 1(7): 825-829, 1992. PMID: 21584623.

67 Hoye AT, Davoren JE, Wipf P, Fink MP and Kagan VE: Targeting mitochondria. Acc Chem Res 41(1): 87-97, 2008. PMID: 18193822. DOI: 10.1021/ar700135m

68 Skvortsov DA, Emashova SK, Kalinina MA and Dontsova OA: Cyanine mitochondrial dye with slightly selective cytotoxicity against A549 cancerous cells. Arch Pharm (Weinheim) 354(3): e2000281, 2021. PMID: 33245149. DOI: 10.1002/ardp.202000281

69 Starenki D and Park JI: Mitochondria-targeted nitroxide, Mito$\mathrm{CP}$, suppresses medullary thyroid carcinoma cell survival in vitro and in vivo. J Clin Endocrinol Metab 98(4): 1529-1540, 2013. PMID: 23509102. DOI: 10.1210/jc.2012-3671

70 Mazzio EA and Soliman KF: Effects of enhancing mitochondrial oxidative phosphorylation with reducing equivalents and ubiquinone on 1-methyl-4-phenylpyridinium toxicity and complex I-IV damage in neuroblastoma cells. Biochem Pharmacol 67(6): 1167-1184, 2004. PMID: 15006552. DOI: 10.1016/j.bcp.2003.11.016 
71 Desai VG, Feuers RJ, Hart RW and Ali SF: MPP(+)-induced neurotoxicity in mouse is age-dependent: evidenced by the selective inhibition of complexes of electron transport. Brain Res 715(1-2): 1-8, 1996. PMID: 8739616. DOI: 10.1016/0006-8993(95)01255-9

72 Garofalo T, Ferri A, Sorice M, Azmoon P, Grasso M, Mattei V, Capozzi A, Manganelli V and Misasi R: Neuroglobin overexpression plays a pivotal role in neuroprotection through mitochondrial raft-like microdomains in neuroblastoma SK-NBE2 cells. Mol Cell Neurosci 88: 167-176, 2018. PMID: 29378245. DOI: $10.1016 /$ j.mcn.2018.01.007

73 Rubio-Osornio M, Orozco-Ibarra M, Díaz-Ruiz A, Brambila E, Boll MC, Monroy-Noyola A, Guevara J, Montes S and Ríos C: Copper sulfate pretreatment prevents mitochondrial electron transport chain damage and apoptosis against $\mathrm{MPP}^{+}$-induced neurotoxicity. Chem Biol Interact 271: 1-8, 2017. PMID: 28442376. DOI: 10.1016/j.cbi.2017.04.016

74 Sablin SO, Krueger MJ, Yankovskaya VL, Tkachenko SE, Razdolsky AN, Bachurin SO, Ramsay RR and Singer TP: Inhibition of NADH oxidation by 1-methyl-4-phenylpyridinium analogs as the basis for the prediction of the inhibitory potency of novel compounds. J Biochem Toxicol 11(1): 33-43, 1996. PMID: 8806050. DOI: 10.1002/(SICI)1522-7146(1996)11:1<33::AIDJBT5>3.0.CO;2-W

75 Annepu J and Ravindranath V: 1-Methyl-4-phenyl-1,2,3,6tetrahydropyridine-induced complex I inhibition is reversed by disulfide reductant, dithiothreitol in mouse brain. Neurosci Lett 289(3): 209-212, 2000. PMID: 10961666. DOI: 10.1016/s03043940(00)01300-8

76 Choi WS, Kruse SE, Palmiter RD and Xia Z: Mitochondrial complex I inhibition is not required for dopaminergic neuron death induced by rotenone, MPP+, or paraquat. Proc Natl Acad Sci USA 105(39): 15136-15141, 2008. PMID: 18812510. DOI: 10.1073/pnas.0807581105

77 Duz MB and Karatas OF: Expression profile of stem cell markers and $\mathrm{ABC}$ transporters in 5-fluorouracil resistant Hep-2 cells. Mol Biol Rep 47(7): 5431-5438, 2020. PMID: 32627138. DOI: $10.1007 / \mathrm{s} 11033-020-05633-\mathrm{x}$

$78 \mathrm{Kim} \mathrm{J}$ and Cheong JH: Role of mitochondria-cytoskeleton interactions in the regulation of mitochondrial structure and function in cancer stem cells. Cells 9(7), 2020. PMID: 32674438. DOI: 10.3390/cells9071691

79 Rodrigues T and Ferraz LS: Therapeutic potential of targeting mitochondrial dynamics in cancer. Biochem Pharmacol 182: 114282, 2020. PMID: 33058754. DOI: 10.1016/j.bcp.2020. 114282

80 Wang $\mathrm{Z}$ and Dong C: Gluconeogenesis in cancer: Function and regulation of PEPCK, FBPase, and G6Pase. Trends Cancer 5(1): 30-45, 2019. PMID: 30616754. DOI: 10.1016/j.trecan.2018.11.003

81 Moffett JR, Puthillathu N, Vengilote R, Jaworski DM and Namboodiri AM: Acetate revisited: A key biomolecule at the nexus of metabolism, epigenetics and oncogenesis-part 1: acetylCoA, acetogenesis and acyl-coa short-chain synthetases. Front Physiol 11: 580167, 2020. PMID: 33281616. DOI: 10.3389/ fphys.2020.580167

82 Martínez-Reyes I and Chandel NS: Acetyl-CoA-directed gene transcription in cancer cells. Genes Dev 32(7-8): 463-465, 2018. PMID: 29692354. DOI: 10.1101/gad.315168.118

83 Jha V, Galati S, Volpi V, Ciccone L, Minutolo F, Rizzolio F, Granchi C, Poli G and Tuccinardi T: Discovery of a new ATPcitrate lyase (ACLY) inhibitor identified by a pharmacophore- based virtual screening study. J Biomol Struct Dyn: 1-9, 2020. PMID: 32448086. DOI: 10.1080/07391102.2020.1773314

84 Icard P, Wu Z, Fournel L, Coquerel A, Lincet $\mathrm{H}$ and Alifano M: ATP citrate lyase: A central metabolic enzyme in cancer. Cancer Lett 471: 125-134, 2020. PMID: 31830561. DOI: 10.1016/j.canlet.2019.12.010

85 Ciregia F: Mitochondria lysine acetylation and phenotypic control. Adv Exp Med Biol 1158: 59-70, 2019. PMID: 31452135. DOI: 10.1007/978-981-13-8367-0_4

86 Ignatova VV, Jansen PWTC, Baltissen MP, Vermeulen M and Schneider R: The interactome of a family of potential methyltransferases in HeLa cells. Sci Rep 9(1): 6584, 2019. PMID: 31036863. DOI: 10.1038/s41598-019-43010-2

87 Arcidiacono OA, Krejčí J and Bártová E: The distinct function and localization of METTL3/METTL14 and METTL16 enzymes in cardiomyocytes. Int J Mol Sci 21(21): 2020. PMID: 33143367. DOI: 10.3390/ijms21218139

88 Soldner F, Weller M, Haid S, Beinroth S, Miller SW, Wüllner U, Davis RE, Dichgans J, Klockgether T and Schulz JB: MPP+ inhibits proliferation of PC12 cells by a p21(WAF1/Cip1)dependent pathway and induces cell death in cells lacking p21(WAF1/Cip1). Exp Cell Res 250(1): 75-85, 1999. PMID: 10388522. DOI: $10.1006 /$ excr.1999.4504

89 Amo T, Oji Y, Saiki S and Hattori N: Metabolomic analysis revealed mitochondrial dysfunction and aberrant choline metabolism in $\mathrm{MPP}^{+}$-exposed SH-SY5Y cells. Biochem Biophys Res Commun 519(3): 540-546, 2019. PMID: 31537380. DOI: $10.1016 /$ j.bbrc .2019 .09 .031

90 Badisa RB, Darling-Reed SF and Soliman KF: The protective role of D-glucose against 1-methyl-4-phenylpyridinium ion (MPP+): induced mitochondrial dysfunction in C6 astroglial cells. Neurochem Res 35(9): 1413-1421, 2010. PMID: 20508987. DOI: 10.1007/s11064-010-0200-9

91 Wu T, Li Y, Liu B, Zhang S, Wu L, Zhu X and Chen Q: Expression of ferritin light chain (FTL) is elevated in glioblastoma, and FTL Silencing inhibits glioblastoma cell proliferation via the GADD45/JNK pathway. PLoS One 11(2): e0149361, 2016. PMID: 26871431. DOI: 10.1371/journal.pone.0149361

92 Neuteboom ST, Karjian PL, Boyer CR, Beryt M, Pegram M, Wahl GM and Shepard HM: Inhibition of cell growth by NB1011 requires high thymidylate synthase levels and correlates with p53, p21, bax, and GADD45 induction. Mol Cancer Ther 1(6): 377-384, 2002. PMID: 12477050

93 Huang WS, Kuo YH, Kuo HC, Hsieh MC, Huang CY, Lee KC, Lee KF, Shen CH, Tung SY and Teng CC: CIL-102-induced cell cycle arrest and apoptosis in colorectal cancer cells via upregulation of p21 and GADD45. PLoS One 12(1): e0168989, 2017. PMID: 28068431. DOI: 10.1371/journal.pone.0168989

94 Schweich LC, Oliveira EJT, Pesarini JR, Hermeto LC, Camassola M, Nardi NB, Brochado TMM, Antoniolli-Silva ACMB and Oliveira $\mathrm{RJ}$ : All-trans retinoic acid induces mitochondria-mediated apoptosis of human adipose-derived stem cells and affects the balance of the adipogenic differentiation. Biomed Pharmacother 96: 1267-1274, 2017. PMID: 29239820. DOI: 10.1016/j.biopha.2017.11.087

Received February 15, 2021 Revised March 15, 2021 Accepted April 6, 2021 